\title{
Alteração clorítica no flanco leste do Granito Caçapava, Rio Grande do Sul: evolução do metassomatismo e sulfetos de $\mathrm{Cu}-\mathrm{Fe}$ associados

\author{
Chloritic alteration in the east flank of the Caçapava Granite, State of \\ Rio Grande do Sul: metasomatic evolution and associated Cu-Fe sulfides
}

\begin{abstract}
Rafael Souza dos Reis ${ }^{1}$, Marcus Vinicius Dornelles Remus ${ }^{1}$, Norberto Dani ${ }^{1}$, Henrique de Maman Anzolin ${ }^{1}$ ${ }^{1}$ Curso de Pós-Graduação em Geociências, Instituto de Geociências, Universidade Federal do Rio Grande do Sul - UFRGS, Avenida Bento Gonçalves, 9.500, Caixa Postal 15.001, CEP 91501-970, Porto Alegre, RS, BR (sdosreis.rafael@gmail.com; marcus.remus@ufrgs.br; norberto.dani@ufrgs.br; henriqueanzolin@hotmail.com)
\end{abstract}

Recebido em 19 de setembro de 2016; aceito em 9 de outubro de 2017

\begin{abstract}
Resumo
Este trabalho investigou a origem e a evolução de clorititos — rochas portadoras de clorita e/ou sulfetos de Cu-Fe —, associados a sills e apófises do Granito Caçapava que intrudem nos mármores dolomíticos da Formação Passo Feio, Terreno São Gabriel do Escudo Sul-Riograndense (ESRG). A interação dos fluidos graníticos com os mármores gera associações minerais de alta e baixa temperatura. Os halos de alteração de baixa temperatura nos granitoides são constituídos dominantemente por clorita seguida de albita, titanita, sulfetos e raro rutilo. Clorita, calcita e, eventualmente, serpentina, talco e sulfetos constituem a alteração de baixa temperatura nos mármores encaixantes. Os halos de alteração distribuem-se em domínios ao longo da matriz dos granitoides, bem como em stockworks ou em brechas hidrotermais e fraturas contendo calcopirita e pirita. Identificam-se processos importantes de alteração hidrotermal-metassomática, notadamente cloritização e albitização no protólito granitoide. A alteração é progressiva nas apófises granitoides com modificações desde incipiente até rochas compostas majoritariamente por cloritas, culminando com a geração de clorititos. A nucleação e o crescimento da clorita ocorre a partir da substituição da biotita e do plagioclásio ou deposita em espaços vazios na rocha carbonática encaixante. O balanço de massa pelo método da isócona indica que o processo de cloritização evoluiu por meio do enriquecimento de $\mathrm{MgO}$ e $\mathrm{FeO}$ e do empobrecimento em $\mathrm{SiO}_{2}, \mathrm{~K}_{2} \mathrm{O}$ e $\mathrm{Na}_{2} \mathrm{O}$ dos protólitos granitoides. Os padrões de abundância e distribuição de elementos terras raras (ETR) indicam correlação direta das rochas portadoras de clorita e dos clorititos com fácies pertencentes ao Complexo Granítico de Caçapava do Sul. Geotermometria a partir da composição da clorita indica temperatura média entre 280 e $300^{\circ} \mathrm{C}$ para formação das cloritas.
\end{abstract}

Palavras-chave: Clorititos; Alteração hidrotermal; Metassomatismo.

\begin{abstract}
This work investigated the origin and evolution of chloritites and chlorite bearing rocks and $\mathrm{Cu}-\mathrm{Fe}$ sulfides, associated with sill and apophysis of the Caçapava Granite, which intrude in the dolomitic marbles of the Passo Feio formation, Terrane São Gabriel of the Sul-Riograndense Shield. The interaction of the granite fluids with the marbles generates high- and low-temperature mineral associations. The low-temperature alteration halos on the granitoid are mainly constituted of chlorite followed by albite titanite, sulfide and rare rutile. Chlorite, calcite and, eventually, serpentine, talc and sulfides constitute the low-temperature alteration in the country-rock marbles. The alteration halos are distributed in domains along the granitoid matrix as well as in stock-works or in hydrothermals breccias and its related fractures with chalcopyrite and pyrite. Important hydrothermal metassomatic alteration processes have been identified, notably, chloritization and albitization in the granitoid protholite. The alteration is progressive in the granitoid apophyses, with modifications since incipient to the rocks mainly constituted of chlorites, culminating in the generation of chloritites. The nucleation and growth of chlorite develops from the substitution of biotite and of plagioclase, or deposits it in empty spaces of carbonatic country-rocks. The mass balance by the isocon method indicates that the chloritization process developed through the enrichment of $\mathrm{MgO}$ and $\mathrm{FeO}$ and depletion in $\mathrm{SiO}_{2}, \mathrm{~K}_{2} \mathrm{O}$ and $\mathrm{Na}_{2} \mathrm{O}$ in the protholite granitoids. The abundance pattern and distribution of rare-earth element (REE) belonging to Complex Granitic Caçapava do Sul. Geothermometry of chlorite composition indicates an average temperature between 280 and $300^{\circ} \mathrm{C}$ for the chlorite formation.
\end{abstract}

Keywords: Chloritites; Hydrothermal alteration; Metasomatism. 


\section{INTRODUÇÃO}

Clorititos são rochas formadas essencialmente por clorita e são considerados por diversos autores como o produto resultante de um intenso processo hidrotermal. Predominantemente são encontrados associados a alguma zona de alteração hidrotermal, ligados a depósitos exalativos (Schermerhorn, 1978; Miyashiro et al., 1979; McLeod e Stanton, 1984) e a depósitos do tipo Volcanic Massive Sulfide - VMS (Zang e Fyfe, 1995; Ruiz et al., 2002, entre outros), também como resultado de alteração de rochas ultramáficas, como em ofiolitos (Humphris e Thompson, 1978; Mottl e Holland, 1978; Schiffman e Staudigel, 1995). Em outros tipos de jazida, como do tipo pórfiro de $\mathrm{Cu}(\mathrm{Au})$, a ocorrência de clorita pode indicar a presença de zonas mineralizadas alteradas hidrotermalmente. No presente estudo, evidências geoquímicas e petrográficas indicaram a presença da alteração do tipo propilítica nas rochas analisadas, caracterizada pela adição de $\mathrm{H}_{2} \mathrm{O}, \mathrm{CO}_{2}$ e S localmente no sistema, além de assembleia mineral com presença de clorita, albita e titanita, além de carbonatos, pirita e sericita subordinadas (Pirajno, 1992).

Aárea de estudo está localizada no flanco leste do Complexo Granítico de Caçapava do Sul (Bitencourt, 1983; Nardi e Bitencourt, 1989), na região da ocorrência de $\mathrm{Cu}-\mathrm{Au}$ Coronel Linhares (Remus et al., 2000a), onde apófises desse corpo intrudem as rochas carbonáticas deformadas da Formação Passo Feio (Hartmann et al., 2000a) e produzem novas assembleias mineralógicas geradas por alteração hidrotermal-metassomática. Dessa interação entre as rochas carbonáticas e os fluidos magmáticos formam-se escarnitos magnesianos e outras rochas metassomáticas em que se destacam os clorititos (Remus et al., 2011). O halo de alteração apresenta dimensões de centímetros a poucos metros, situado nas apófises do corpo ígneo intrusivo.

Nos mármores pertencentes à Formação Passo Feio, a dolomita é o carbonato predominante e ocorre como grãos subédricos e euédricos com textura granoblástica (Ribeiro e Carraro, 1971; Bortolotto, 1988; Remus et al., 2000a; Goulart et al., 2013). Uma paragênese associada aos mármores e alteração clorítica ocorre ao longo dos contatos entre as apófises do corpo intrusivo e os mármores encaixantes. Nessa ocorrência, os minerais calcita, talco, serpentina, clorita, tremolita e diopsídio estão relacionados majoritariamente aos sulfetos pirita, calcopirita, pirrotita e molibdenita (Remus et al., 2011). Localmente, os sulfetos também estão combinados com clorita em brechas hidrotermais.

$\mathrm{O}$ forte metassomatismo magnesiano foi o mecanismo responsável pela transformação progressiva do biotita granodiorito em rochas cloríticas nas paredes ao longo do contato com os mármores dolomíticos (Remus et al., 2000a).

Esse estudo, de caráter analítico geoquímico, objetivou buscar uma melhor compreensão sobre o processo de interação metassomática. Para tal, foi apresentada a indispensável investigação entre as apófises graníticas - como produto inicial - e as rochas cloritíticas - como produto final desse processo. Somado a esse estudo, neste trabalho caracterizou-se petrograficamente as rochas e aplicou-se métodos empíricos de geotermometria. Visando a melhor compreensão da interação metassomática entre as apófises ígneas e as rochas encaixantes, os dados petrográficos e químicos são apresentados no sentido de reforçar a interpretação e a proposição das principais condições físico-quimicas dos processos responsáveis pela deposição da clorita e da mineralização $\mathrm{Cu}$-Au associada.

\section{Geologia regional}

O Escudo Sul Rio-Grandense (ESRG), localizado na porção sul da Província Mantiqueira (Almeida et al., 1976), é definido como produto de dois ciclos orogênicos: Transamazônico (2260-2000 Ma) e Brasiliano (900-535 Ma). O ESRG (Figura 1) possui quatro porções: Taquarembó, São Gabriel, Tijucas e Batólito Pelotas. As divisões do ESRG são encontradas em distintas publicações descritas como Domínio, Bloco ou Terreno para as porções Taquarembó e São Gabriel; e Cinturão ou Terreno para a porção Tijucas (Chemale Jr., 2000; Hartmann et al., 2007).

O Bloco São Gabriel (BSG) registra um evento orogênico (Jost e Hartmann, 1984) que pertence juntamente com o evento Dom Feliciano ao ciclo Brasiliano. O evento São Gabriel apresenta idades entre 860 e $680 \mathrm{Ma}$, enquanto o evento Dom Feliciano registra idades entre 650 e $535 \mathrm{Ma}$ (Chemale Jr. et al., 1994; Babinski et al., 1996, 1997; Hartmann et al., 2000b, 2007, 2011; Chemale Jr., 2000). Alvo deste estudo, a ocorrência dos clorititos está diretamente ligada à interação entre a Formação Passo Feio e a intrusão do Complexo Granítico de Caçapava do Sul, os quais estão situados neste contexto.

\section{Formação Passo Feio}

A Formação Passo Feio (Hartmann et al., 2000a) é uma sequência metamórfica vulcanossedimentar em fácies anfibolito inferior e constituída por ardósias, filitos, xistos pelíticos e magnesianos, mármores, quartzitos, metaconglomerados, rochas cálcio-silicatadas, anfibolitos e subordinadamente metabasaltos, que preserva estrutura ígnea do protólito. $\mathrm{O}$ metamorfismo regional que afeta a associação litológica varia entre a zona da clorita da fácies xisto verde e a zona da estaurolita da fácies anfibolito (Ribeiro et al., 1966; Bitencourt, 1983; Hartmann et al., 1990). Datações K/Ar realizadas por Soliani Jr. (1986) indicam idades entre 666 e 556 Ma. Ocorrências de cobre são controladas por estruturas de direção NE do Sistema de Falhas Irapuá ou estão associadas a fraturas extensionais transversais na direção NW (Remus et al., 2000a). A intrusão do Granito Caçapava (562 Ma), datada pelo método SHRIMP - Sensitive High Resolution Ion Microprobe (Remus et al., 2000a), promove efeitos termais significativos nas rochas encaixantes da Formação Passo Feio. A ocorrência de $\mathrm{Cu}(\mathrm{Au})$ Coronel 
Linhares está localizada próxima do contato do corpo ígneo e dos mármores encaixantes (Remus et al., 2000a).

\section{Complexo Granítico de Caçapava do Sul}

O Complexo Granítico de Caçapava do Sul (Bitencourt, 1983) ou Granito Caçapava (Ribeiro et al., 1966) é um batólito com forma assimétrica e estrutura alongada na direção N-S. Apófises com mergulho sub-horizontal intrudem as rochas encaixantes no lado leste e na porção central. Na porção oeste do batólito, os mergulhos variam entre 40 e $70^{\circ}$ para NW (Ribeiro et al., 1966; Bitencourt, 1983; Sartori e Kawashita, 1985; Nardi e Bitencourt, 1989). O Complexo Granítico de Caçapava do Sul é constituído por três fácies:

1. biotita granitoides: com rochas que variam entre granodiorito, tonalito, quartzo monzodiorito a quartzo diorito;

2. leucogranitoides: com rochas entre sienogranitos a granodioritos; e

3. granitoides transicionais: com rochas entre monzogranito e granodiorito, principalmente (Nardi e Bitencourt, 1989).
A biotita é o principal mineral varietal, enquanto a hornblenda, alanita e granada são subordinados. Estudos geoquímicos indicam afinidade cálcio-alcalina e composição dominantemente metaluminosa e peraluminosa em rochas mais diferenciadas (Nardi e Bitencourt, 1989).

O Granito Caçapava foi derivado de processos de fusão da crosta, sendo síncrono com o evento de deformação regional da área (Bitencourt, 1983; Nardi e Bitencourt, 1989; Costa et al., 1995; Remus et al., 2000a). Na borda leste e sudeste do corpo ocorrem intrusões sub-horizontais nos mármores pertencentes à Formação Passo Feio (Figura 2A). A foliação de baixo ângulo está relacionada provavelmente com a zona de cisalhamento transcorrente ligada à sutura de Caçapava (Costa et al., 1995) do evento de deformação regional que afetou o Granito Caçapava (Remus et al., 2000a).

\section{Geologia da área de estudo}

O metassomatismo que ocorre devido à interação entre as apófises intrusivas do Granito Caçapava e os mármores da Formação Passo Feio gera na porção sul da área da ocorrência

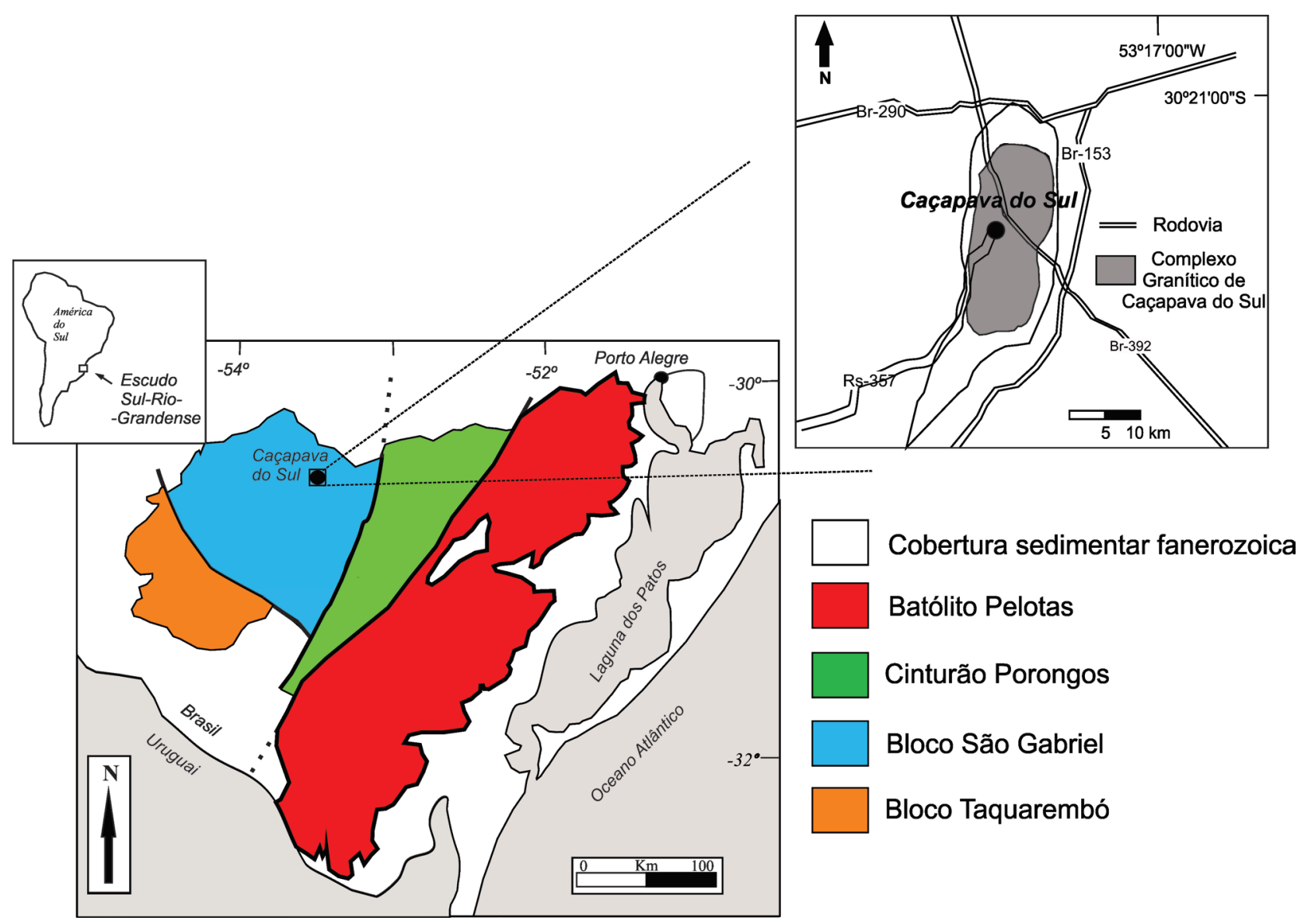

Fonte: modificado de Remus et al., 2000b.

Figura 1. Mapa com a compartimentação geotectônica do Escudo Sul Rio-Grandense. 
Coronel Linhares duas associações mineralógicas restritas e distintas por suas características estruturais e de temperatura. Uma fase, de mais alta temperatura, caracteriza-se pela presença de estruturas dúcteis e paragênese mineralógica constituída majoritariamente por olivina, diopsídio, tremolita, pirrotita e molibdenita. Outra fase, de mais baixa temperatura, é caracterizada pela paragênese mineralógica talco, calcita, serpentina e clorita, juntamente com pirita e calcopirita. Nas porções leste e norte da área de estudo (Figura 2A) ocorrem halos de alteração que evoluem das apófises graníticas para rochas cloritíticas, caracterizando a presença de endoskarn. As intrusões apresentam foliação sub-horizontal concordante com a estrutura das rochas carbonáticas encaixantes (Figura 2B).

\section{MÉTODOS APLICADOS E ATIVIDADES DESENVOLVIDAS}

Para execução deste trabalho foram utilizadas técnicas analíticas distintas, tais como petrografia, análise química de rocha total e de minerais individuais. Na área foram selecionadas sete amostras representantes das fases pré-alteração, intermediária e pós-alteração hidrotermal, localizadas nas apófises situadas nas porções leste e norte para determinação da composição por análise química de rocha total. Após a cominuição até a fração de 200 mesh as análises químicas foram executadas no laboratório Acme Analytical Ltda. pelo método FUS-ICPES (Fusion Inductively Coupled PlasmaEmission Spectrometry), para a determinação da concentração dos elementos maiores, e pelo método FUSICP-MS (Fusion Inductively Coupled Plasma - Mass Spectrometry), para a determinação da concentração dos elementos menores e traço. Lâminas petrográficas foram analisadas em microscópio petrográfico equipado com câmera digital para identificação da mineralogia e da textura.

Para análise composicional da biotita, plagioclásio e clorita, utilizou-se microssonda eletrônica Cameca SXFive, no Laboratório de Microssonda Eletrônica do Centro de Estudos em Petrologia e Geoquímica do Instituto de Geociências da Universidade Federal do Rio Grande do Sul (CPGq/IGeo/ UFRGS). Os parâmetros utilizados foram: voltagem de aceleração de $15 \mathrm{keV}$, corrente de $15 \mathrm{nA}$ e feixe de $5 \mu \mathrm{m}$.

Para analisar a mobilidade química dos elementos foi utilizado o método de isóconas proposto por Grant (1986, 2005) por meio do software Easy Gres Grant (López-Moro, 2012). Esse método permite a comparação direta da mobilidade química entre a rocha alterada e a não alterada em um diagrama das isóconas. Foram gerados diagramas de isóconas e a determinação dos ganhos e das perdas das variáveis volume, massa e mobilidade química entre as rochas, sendo valores positivos para ganhos e valores negativos para perdas. Para determinação da temperatura de formação da

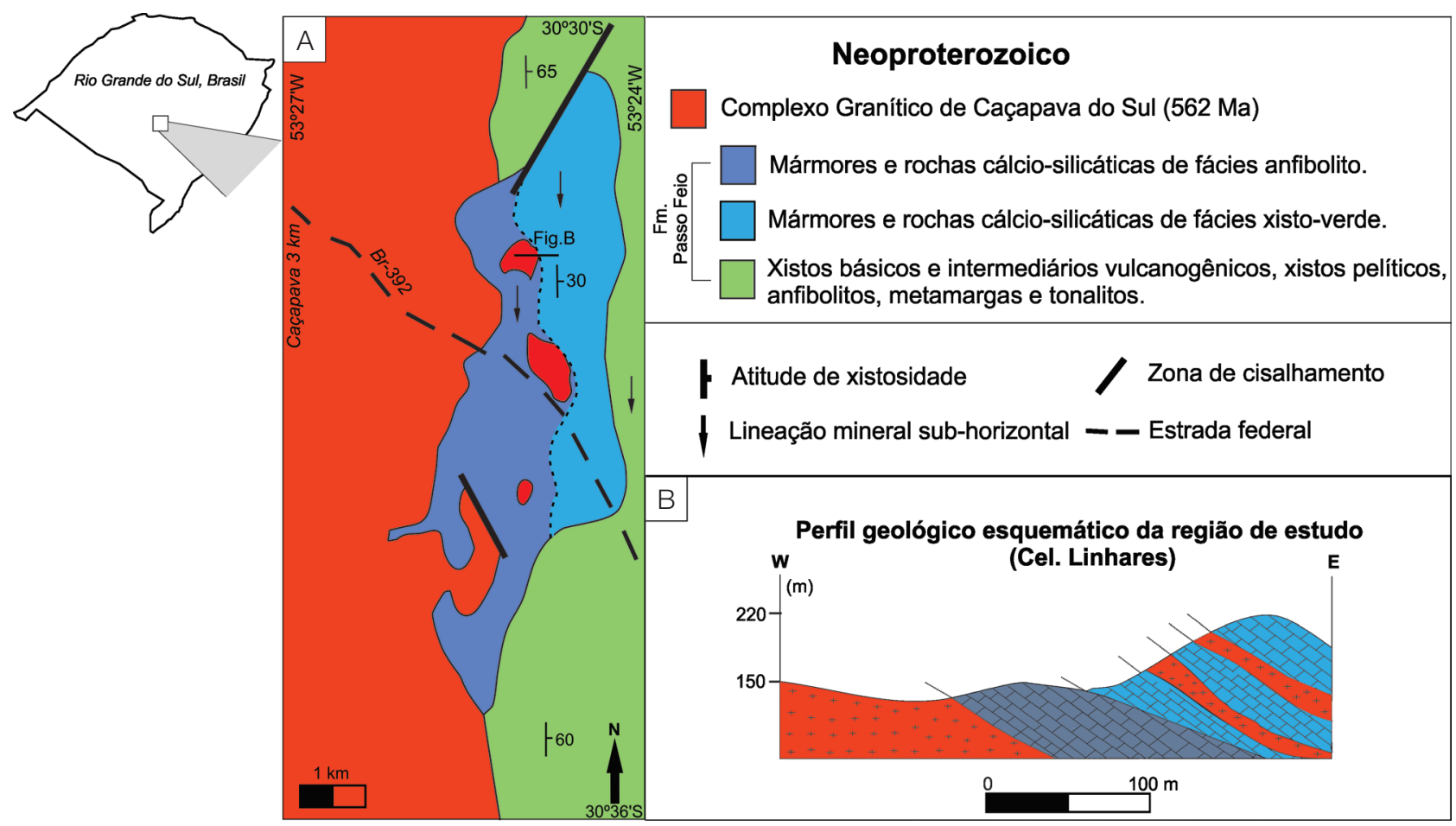

Figura 2. Mapa geológico da área de estudo com apófises ígneas intrudindo nos mármores dolomíticos encaixantes no flanco leste do corpo granítico. (A) Mapa geológico regional (modificado de Bortolotto, 1988); (B) perfil geológico esquemático referente à ocorrência Coronel Linhares, alvo do estudo. 
clorita foram utilizados dois métodos de geotermometria empírica baseados no grau de participação do $\mathrm{Al}$ e a vacância em nível octaédrico proposta por Cathelineau (1988) e Kranidiotis e MacLean (1987). Para o estudo, considera-se que a maior parte do Fe presente na clorita está na forma $\mathrm{Fe}^{+2}$, com o Fe${ }^{+3}$ participando com menos de $5 \%$ da composição total (Foster, 1962; Deer et al., 1966) em cristais de clorita com fórmula química baseada em 28 oxigênios.

\section{RESULTADOS}

\section{Relações de campo e a alteração progressiva das rochas}

Na região de estudo, os clorititos são formados progressivamente a partir das reações de interação entre as apófises ígneas e as rochas encaixantes (Figura 2B), provocando um halo de alteração com dimensão de poucos metros. A proporção de alteração no protólito (granitoides) aumenta em direção ao norte da área de estudo, sendo macroscopicamente perceptível por meio de alterações na cor da rocha. A interação com os mármores dolomíticos é evidenciada pela paragênese cálcio-silicática identificada nos contatos (Figura 3A) entre a intrusão ígnea e os mármores encaixantes. Nas apófises a foliação é concordante com as rochas encaixantes e é melhor observada com o aumento progressivo da alteração e a formação de uma nova associação mineralógica. As fraturas presentes possuem alto mergulho e direção com distribuição randômica. Os granitoides estudados possuem leve coloração avermelhada devido a processos de albitização (Figura 3B) e índice M' variável (8-15). A alteração progressiva modifica a coloração da rocha, sendo o processo evidenciado pelo aumento da presença de minerais máficos
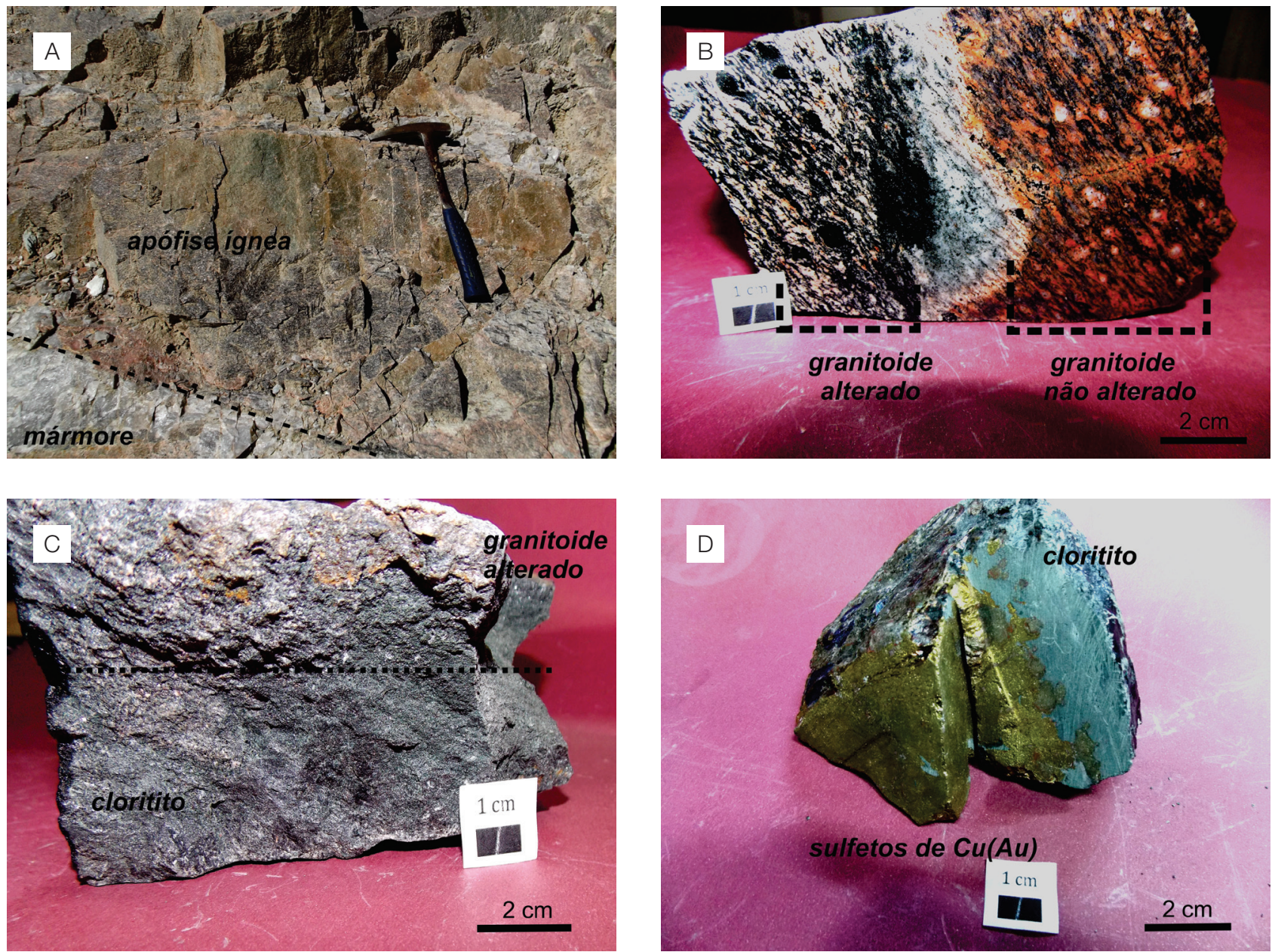

Figura 3. Imagens da relação de campo local e amostras coletadas para o estudo. (A) Apófise ígnea em contato com o mármore encaixante; (B) granitoide não alterado (direita) em contato com granitoide alterado metassomaticamente (esquerda). Granitoide não alterado pertence a fácies biotita-granitoides; (C) granitoide portador de clorita progressivamente alterando para cloritito; (D) hidrotermalito composto por cloritito associado a sulfetos de $\mathrm{Cu}(\mathrm{Au})$. 
(Figura 3B). Com o avanço da alteração, a coloração da rocha vai sendo modificada com a consequente formação dos clorititos (Figuras 3C e 3D).

\section{Petrografia}

Os granitoides estudados apresentam majoritariamente granulação média e localmente incipiente foliação e/ou lineação marcada pela orientação dos cristais de biotita. Ocorrem, isoladamente, minerais de feldspato potássico com granulação grossa, provavelmente resultante de estágios tardios de cristalização. A biotita é o mineral máfico abundante e apresenta pleocroísmo que varia entre as cores amarela-escura a marrom-castanho. Entre os acessórios, o zircão é o mineral mais facilmente encontrado, seguido por titanita e raro epídoto. Os clorititos estudados, de forma geral, apresentam granulação fina a média e foliação marcada pela orientação da clorita, que, juntamente com a albita (subordinada), são os minerais de alteração predominantes na rocha. A clorita apresenta pleocroísmo em tons de verde-claro a verde-escuro em luz natural, enquanto em luz polarizada é encontrado em tons de cinza e azul-berlim. A cloritização das rochas é evidenciada inicialmente pela substituição da biotita (Figura 4A). Com a progressiva alteração, formam-se agregados de clorita (Figura 4B). Os hábitos comuns da clorita são o lamelar e o radial (Figura 4C). Este, por vezes, apresenta coloração em tons de azul. A albitização (Figura 4D) associa-se aos feldspatos. O quartzo hidrotermal é encontrado localmente com hábito hexagonal e extinção ondulante contendo frequentemente uma coroa que cresce radialmente sobre núcleos do próprio quartzo (Figura 4E). Minerais acessórios como titanita, rutilo, carbonato e zircão são encontrados de forma esparsa e associados à paragênese mineral pré e pós-alteração (Figura 4F). Os sulfetos predominantes são a pirita e a calcopirita, frequentemente de forma maciça e associados dominantemente aos clorititos. Hematita é rara e ocorre substituindo minerais opacos. Por meio das observações petrográficas é possível estabelecer uma relação e uma ordem cronológica de formação da paragênese mineral nos estágios de alteração (Tabela 1).

\section{Geoquímica}

Para análise química de rocha total, foram selecionadas sete amostras representantes dos estágios inicial e final do processo de alteração. Do conjunto de amostras analisadas (Tabela 2), quatro (SL1, GR1-A, GR1-B, GR2) representam o protólito (granitoide) e três, os clorititos (CL1, CL2 e CL3). A composição química dos granitoides analisados (Tabela 2) apresenta variação composicional (Figura 5A), estando esses dentro do campo das rochas peraluminosas (Figura 5B), típica das fácies mais diferenciadas do Complexo
Granítico Caçapava do Sul. A composição química dos clorititos (Tabela 2) apresenta elevado $\mathrm{MgO}$ e baixa quantidade de $\mathrm{SiO}_{2}$. Os Diagramas de Harker (Figura 6) mostram a variabilidade composicional entre as rochas protólito e os clorititos. Os diagramas caracterizam o empobrecimento de $\mathrm{SiO}_{2}$ nos clorititos, bem como o empobrecimento de $\mathrm{CaO}$, $\mathrm{Na}_{2} \mathrm{O}$ e $\mathrm{K}_{2} \mathrm{O}$. No entanto, $\mathrm{TiO}_{2}$ e $\mathrm{P}_{2} \mathrm{O}_{5}$ se mantêm equivalentes durante o processo, enquanto $\mathrm{Al}_{2} \mathrm{O}_{3}$ apresenta um leve enriquecimento e $\mathrm{FeO}$ e $\mathrm{MgO}$ enriquecem fortemente.

\section{Mobilidade química}

O método simplificado de Gresens (1967) adaptado por Grant $(1986,2005)$ foi aplicado no estudo da mobilidade química entre as rochas na fase pré-, sin- e pós-alteração hidrotermal. Esse método permite a comparação direta da mobilidade química entre a rocha alterada e a não alterada em um diagrama das isóconas. Na análise quantitativa (Tabela 3) é avaliado o comportamento dos elementos químicos durante o processo de alteração. $\mathrm{Al}_{2} \mathrm{O}_{3}$ e TiO 2 são considerados os óxidos imóveis em sistemas hidrotermais (Rollinson, 1993). O Hf e o Zr são elementos de alta intensidade de campo e pequeno raio iônico e são considerados os elementos mais imóveis em soluções aquosas (Rollinson, 1993). Quando um elemento é considerado imóvel e utilizado para definir uma isócona, interpreta-se que houve uma transferência muito pequena de massa ou ainda que a concentração de um componente relativo a outro não muda, formando um par químico. Para este trabalho foi excluído o $\mathrm{Al}_{2} \mathrm{O}_{3} \mathrm{em}$ função de sua mobilidade relativa; sendo assim, $\mathrm{TiO}_{2}, \mathrm{Zr}$ e Hf foram considerados imóveis para a determinação das isóconas. As amostras GR1-B, GR1-A e CL1 foram selecionadas para observação da mobilidade química das fases de pré-alteração, intermediária e rocha alterada. Os critérios de seleção das amostras para utilização da técnica foram a relação proximal de campo e o aumento progressivo de alteração, perceptível por meio de informações químicas e petrográficas, como a presença de clorita. Seguindo os critérios, a amostra GR1-B representa a fase pré-alteração; a amostra GR1-A, a fase intermediária; e a amostra CL1, a fase alterada. $\mathrm{Na}$ análise da mobilidade química entre as fases pré-alteração e intermediária (Figuras 7A e 7B) nota-se um enriquecimento de $\mathrm{Fe}_{2} \mathrm{O}_{3}, \mathrm{MgO}$ e $\mathrm{Na}_{2} \mathrm{O}$, o que sugere a caracterização dos processos de cloritização e albitização, visto que, juntamente, ocorre um leve empobrecimento de $\mathrm{SiO}_{2}, \mathrm{CaO}$ e $\mathrm{K}_{2} \mathrm{O}$. Os outros óxidos podem ser considerados como relativamente imóveis nessa relação. Na mobilidade química entre as fases intermediária e rocha alterada (Figuras 7C e 7D) nota-se um enriquecimento relativo maior de $\mathrm{Fe}_{2} \mathrm{O}_{3}$ e $\mathrm{MgO}$, porém entre os óxidos empobrecidos está o $\mathrm{Na}_{2} \mathrm{O}$, juntamente com $\mathrm{SiO}_{2}, \mathrm{Al}_{2} \mathrm{O}_{3}$, $\mathrm{CaO}$ e $\mathrm{K}_{2} \mathrm{O}$. Para uma interpretação direta entre produto inicial e final do processo de alteração é importante a relação 
entre as amostras GR1-B e CL1 (Figuras 7E e 7F). Nota-se o enriquecimento de $\mathrm{Fe}_{2} \mathrm{O}_{3}$ e $\mathrm{MgO}$ e a diminuição com a alteração dos teores de $\mathrm{SiO}_{2}, \mathrm{CaO}, \mathrm{K}_{2} \mathrm{O}$ e $\mathrm{Na}_{2} \mathrm{O}$. Entre os elementos menores pode ser destacado o empobrecimento de $\mathrm{Ba}, \mathrm{Sr}, \mathrm{Rb}$. O empobrecimento de $\mathrm{Na}_{2} \mathrm{O}$ entre as fases intermediária e final e na relação direta entre as etapas
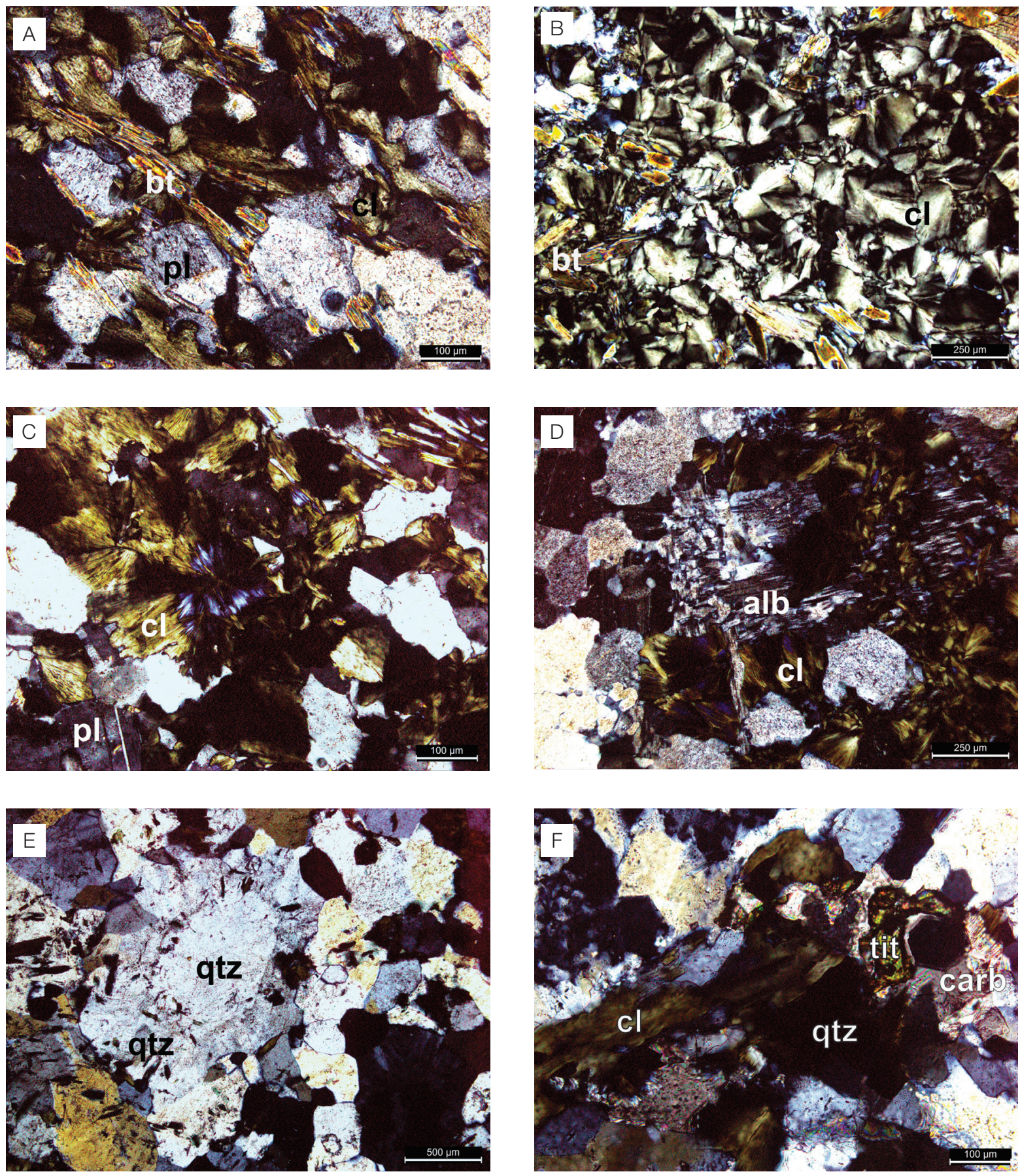

pl: plagioclásio; kf: K-feldspato; bt: biotita; cl: clorita; alb: albita; tit: titanita; rut: rutilo; qtz: quartzo; carb: carbonato.

Figura 4. Fotomicrografias envolvendo aspectos petrográficos das rochas estudadas. As fotomicrografias $(A),(B),(C)$ e (F) pertencem à amostra GR 1; e as fotomicrografias (D) e (E), à amostra Cel. (A) Início de alteração da biotita para clorita; (B) processo de cloritização mais intensa com concentração de cloritas; (C) hábito fibro-radial da clorita; (D) processo de albitização em plagioclásio; (E) presença de quartzo hidrotermal; (F) paragênese mineral principal resultante da alteração (clorita e albita) adjunto a minerais traços (carbonato, titanita e quartzo). 
Tabela 1. Sequência da paragênese mineral simplificada para a associação encontrada nos estágios da alteração hidrotermal presente nas rochas estudadas.

\begin{tabular}{|c|c|c|c|c|}
\hline Mineral & Pré-alteração & $\begin{array}{c}\text { Estágio } \\
\text { inicial }\end{array}$ & $\begin{array}{c}\text { Estágio } \\
\text { intermediário }\end{array}$ & $\begin{array}{c}\text { Estágio } \\
\text { final }\end{array}$ \\
\hline \\
\hline Carbonato & & & & \\
\hline \multicolumn{5}{|l|}{ Feldspato potássico } \\
\hline \multicolumn{5}{|l|}{ Biotita } \\
\hline \multicolumn{5}{|l|}{ Plagioclásio } \\
\hline \multicolumn{5}{|l|}{ Clorita } \\
\hline \multicolumn{5}{|l|}{ Albita } \\
\hline \multicolumn{5}{|l|}{ Titanita } \\
\hline \multicolumn{5}{|l|}{ Rutilo } \\
\hline \multicolumn{5}{|l|}{ Alanita/Epídoto } \\
\hline \multicolumn{5}{|l|}{ Pirita } \\
\hline \multicolumn{5}{|l|}{ Calcopirita } \\
\hline Hematita & & & & \\
\hline
\end{tabular}
Abundante

Comum

Raro

Tabela 2. Composição química das amostras. Concentrações dos elementos maiores (wt\%) e dos elementos-traços (ppm).

\begin{tabular}{|c|c|c|c|c|c|c|c|}
\hline Amostra & SL-1 & GR1-A & GR1-B & GR2 & CL1 & CL2 & CL3 \\
\hline \multicolumn{8}{|l|}{$\mathrm{Wt}(\%)$} \\
\hline $\mathrm{SiO}_{2}$ & 60,09 & 62,32 & 71,04 & 69,22 & 34,90 & 44,73 & 38,36 \\
\hline $\mathrm{TiO}_{2}^{2}$ & 0,58 & 0,36 & 0,28 & 0,40 & 0,29 & 1,15 & 0,32 \\
\hline $\mathrm{Al}_{2} \mathrm{O}_{3}$ & 18,23 & 15,56 & 14,96 & 14,75 & 18,80 & 17,92 & 18,36 \\
\hline $\mathrm{Fe}_{2}^{2} \mathrm{O}_{3}$ & 3,58 & 5,85 & 2,16 & 3,14 & 17,24 & 11,59 & 14,23 \\
\hline $\mathrm{MnO}$ & 0,04 & 0,03 & 0,01 & 0,03 & 0,08 & 0,04 & 0,06 \\
\hline $\mathrm{MgO}$ & 3,45 & 5,36 & 1,07 & 1,28 & 16,84 & 12,28 & 16,65 \\
\hline $\mathrm{CaO}$ & 1,88 & 0,82 & 1,37 & 1,65 & 0,43 & 0,60 & 0,36 \\
\hline $\mathrm{Na}_{2} \mathrm{O}$ & 5,12 & 5,48 & 3,86 & 3,52 & 1,71 & 4,25 & 2,46 \\
\hline $\mathrm{K}_{2} \mathrm{O}$ & 4,49 & 0,88 & 3,74 & 4,04 & 0,29 & 0,40 & 0,27 \\
\hline $\mathrm{P}_{2}^{2} \mathrm{O}_{5}$ & 0,15 & 0,14 & 0,10 & 0,17 & 0,15 & 0,26 & 0,17 \\
\hline $\mathrm{LOI}^{2}$ & 2,00 & 3,00 & 1,10 & 1,40 & 8,90 & 6,40 & 8,40 \\
\hline $\mathrm{Fe}_{2} \mathrm{O}_{3}{ }^{*}$ & 2,08 & 1,86 & 1,78 & 1,90 & 1,79 & 2,65 & 1,82 \\
\hline $\mathrm{FeO}^{*}$ & 1,35 & 3,59 & 0,34 & 1,12 & 13,90 & 8,04 & 11,17 \\
\hline Total & 99,61 & 99,80 & 99,69 & 99,60 & 99,63 & 99,62 & 99,64 \\
\hline \multicolumn{8}{|l|}{ (ppm) } \\
\hline $\mathrm{Ba}$ & 1434,00 & 195,00 & 1657,00 & 2252,00 & 37,00 & 57,00 & 39,00 \\
\hline Co & 5,10 & 4,10 & 2,90 & 5,50 & 6,20 & 8,40 & 9,20 \\
\hline Cs & 19,40 & 1,50 & 1,70 & 2,90 & 1,90 & 1,30 & 1,70 \\
\hline $\mathrm{Ga}$ & 23,70 & 13,20 & 14,20 & 15,90 & 22,30 & 18,00 & 21,90 \\
\hline $\mathrm{Hf}$ & 8,00 & 4,70 & 4,60 & 6,70 & 7,00 & 10,10 & 7,90 \\
\hline $\mathrm{Nb}$ & 19,90 & 12,90 & 10,00 & 14,80 & 10,70 & 16,30 & 9,20 \\
\hline $\mathrm{Ni}$ & 8,40 & 5,70 & 3,60 & 4,00 & 10,80 & 23,60 & 11,00 \\
\hline $\mathrm{Rb}$ & 193,30 & 31,40 & 85,90 & 85,20 & 13,90 & 15,50 & 13,80 \\
\hline Sc & 9,00 & 4,00 & 3,00 & 5,00 & 4,00 & 17,00 & 5,00 \\
\hline $\mathrm{Sn}$ & 27,00 & 2,00 & 2,00 & 2,00 & 3,00 & 3,00 & - \\
\hline $\mathrm{Sr}$ & 535,80 & 299,60 & 519,50 & 469,30 & 81,60 & 128,20 & 58,70 \\
\hline $\mathrm{Ta}$ & 1,40 & 1,10 & 0,80 & 1,30 & 0,90 & 0,80 & 0,60 \\
\hline Th & 17,10 & 8,60 & 6,30 & 10,70 & 10,60 & 7,60 & 6,30 \\
\hline$U$ & 4,90 & 1,40 & 1,50 & 2,00 & 1,40 & 2,20 & 1,60 \\
\hline V & 56,00 & 35,00 & 23,00 & 33,00 & 37,00 & 122,00 & 46,00 \\
\hline W & 1,10 & - & - & 0,70 & - & 1,70 & 0,60 \\
\hline$Y$ & 20,60 & 13,90 & 10,50 & 14,90 & 16,60 & 47,20 & 15,90 \\
\hline $\mathrm{Zr}$ & 284,30 & 182,60 & 178,70 & 257,70 & 264,80 & 380,70 & 321,70 \\
\hline
\end{tabular}

${ }^{*} \mathrm{FeO}$ e $\mathrm{Fe}_{2} \mathrm{O}_{3}$ calculados pelo método de Jensen, 1976; (-): valores abaixo do limite de detecção. 
inicial e final pode ser explicado pela ausência de albitização ou por uma cloritização relativamente maior do que em outros processos.

\section{Comportamento dos elementos terras raras}

O comportamento dos elementos terras raras (ETR) durante a alteração hidrotermal demonstra que, em geral, as paragêneses dos minerais acessórios controlam a sua distribuição, mas necessariamente não definem mudanças na curva de padrão de abundância (Bowden e Whitley, 1974; Alderton et al., 1980; Baker, 1985; Morteani et al., 1986; Cathelineau, 1987; Ward et al., 1992). A concentração química das sete amostras analisadas (Tabela 4) apresenta valores de ETR entre 144,2 e 495,8 ppm. O $\sum$ ETRL (elementos terras raras leves) tem valores entre 136,0 e $457,3 \mathrm{ppm}$, enquanto o $\sum$ ETRP (elementos terras raras pesados) está entre 7,4 e 35,3 ppm. Os valores da razão $\sum E T R L / \sum E T R P$ está entre 13,0 e 22,9. Das amostras analisadas, os granitoides possuem um total de ETR entre 144,2 e 282,2 ppm e apresentam fracionamento moderado (Figura 8A) com tendência a um enriquecimento maior dos ETRL. O padrão das curvas de abundância apresenta similaridade, exceto a amostra GR1-B, que apresenta um leve empobrecimento de $\mathrm{Sm}$. As razões de $(\mathrm{La} / \mathrm{Sm}) \mathrm{N}$ têm valores entre 5,9 e 7,6 (Tabela 4). Os ETRP dos granitoides possuem um fraco fracionamento e valores entre 7,4 e 15,2, enquanto para as razões de $(\mathrm{Lu} / \mathrm{Gd}) \mathrm{N}$ os valores estão entre 0,42 e 0,50 . Os valores de $(\mathrm{La} / \mathrm{Lu}) \mathrm{N}$ para essas rochas estão entre 24,09 e 32,88, sendo que a amostra GR1-A apresenta o maior valor. A amostra SL1 apresenta um discreto enriquecimento em Er.

Os clorititos possuem $\sum$ ETR entre 266,7 e 495,8 ppm e uma curva de abundância com padrões similares aos granitoides referidos anteriormente (Figura 8B). O $\sum$ ETRL dos clorititos variam entre 254,0 e 457,3 ppm, sendo a amostra CL2 a mais enriquecida. O $\sum$ ETRP dos clorititos apresentam valores entre 11,36 e 35,28 ppm (Tabela 4). Os valores da razão $(\mathrm{La} / \mathrm{Sm}) \mathrm{N}$ estão entre 4,2 e 6,7, enquanto a razão $(\mathrm{Lu} / \mathrm{Gd}) \mathrm{N}$ apresenta valores entre 0,37 e 0,44 . Os valores de $(\mathrm{La} / \mathrm{Lu}) \mathrm{N}$ para os clorititos estão entre 16,7 e 33,1. Os clorititos são mais ricos em ETRL, o que não se reflete nos ETRP, que possuem um enriquecimento discreto. Os clorititos analisados apresentam similaridades quando correlacionados às rochas de fácies biotita-granitoides e granitoides transicionais (Figura 8C), classificados por Nardi e Bitencourt (1989). Quando comparados ao comportamento dos terras raras dos granitoides da área (Figura 8D), representado pelo domínio demarcado no gráfico, nota-se um enriquecimento da amostra CL2 já mencionado. O comportamento do espectro dos ETR relacionado ao tipo de alteração hidrotermal e suas mudanças é sugerido por Taylor e Fryer (1980;1982;1983 apud Pirajno, 1992). Nas suas definições, encontra-se similaridade no espectro dos clorititos estudados com a alteração hidrotermal do tipo propilítica. Os espectros de ETR ligados à alteração propilítica sugeridos pelos autores ainda contêm variações de ETRP similares às encontradas na amostra CL2, apresentando o mesmo enriquecimento seletivo de $\mathrm{Er}$ e $\mathrm{Yb}$.

\section{Química mineral}

Analisou-se 13 grãos de biotita, 11 de plagioclásio e 46 de clorita inseridos na assembleia mineral do estudo.

A composição química dos cristais de biotita (Tabela 5) no granitoide não alterado indica que a rocha pertence à série magmática cálcio-alcalina (Figura 9A).
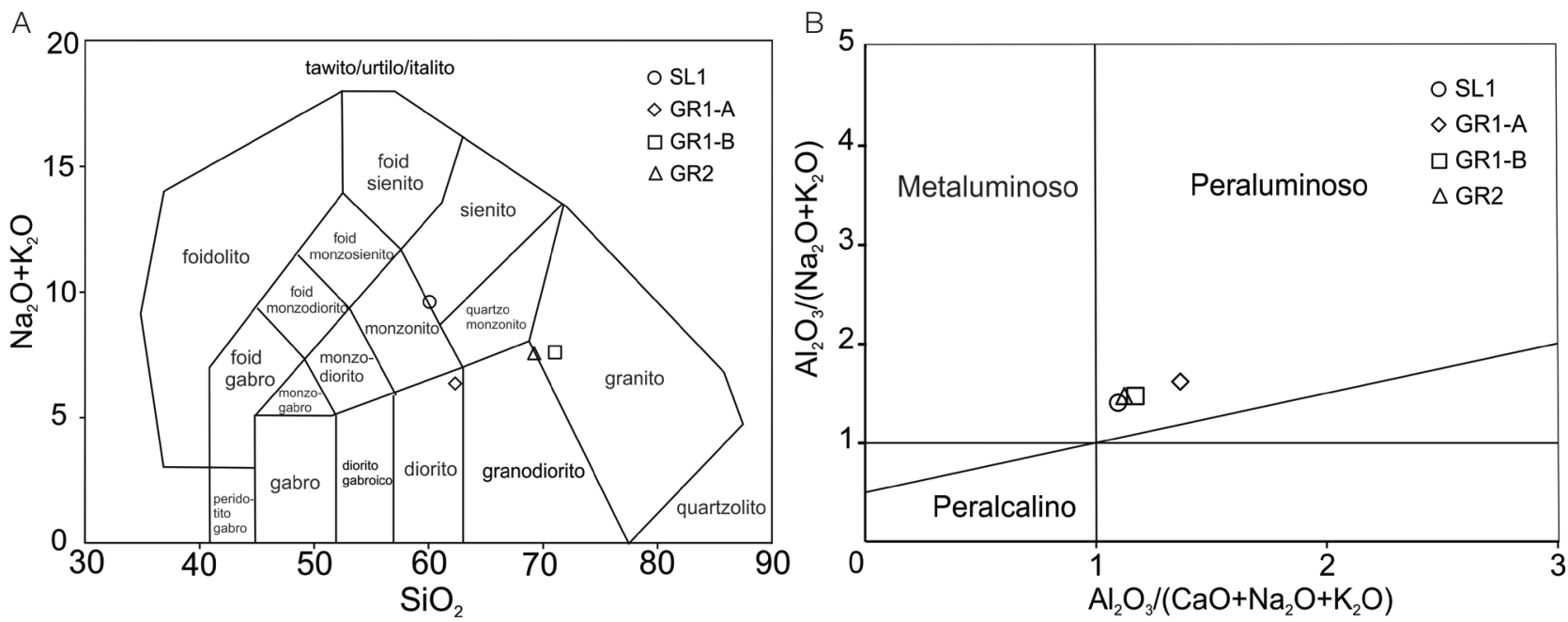

Figura 5. Classificação química dos granitoides analisados. (A) Classificação das rochas ígneas no diagrama de Middlemost (1994); (B) Diagrama de índice de Shand (Rollinson, 1993). 
Os cristais de plagioclásios indicam, por meio da sua composição química em granitoide alterado (Tabela 6), que podem ser classificados majoritariamente como albita.

A Figura 9B apresenta tendência de perda de $\mathrm{TiO}_{2}$ na formação da clorita, comparando-se a biotita presente na rocha ígnea e no estágio inicial do processo. A síntese da composição química da clorita (Tabela 7), em granitoide alterado e hidrotermalito, é classificada como pycnochlorita, majoritariamente, e ripidolita, de forma subordinada (Figura 9C), segundo Hey (1954). A análise da clorita indica leve enriquecimento de Fe do centro para a borda do mineral, bem como o estudo de Remus et al. (2011).
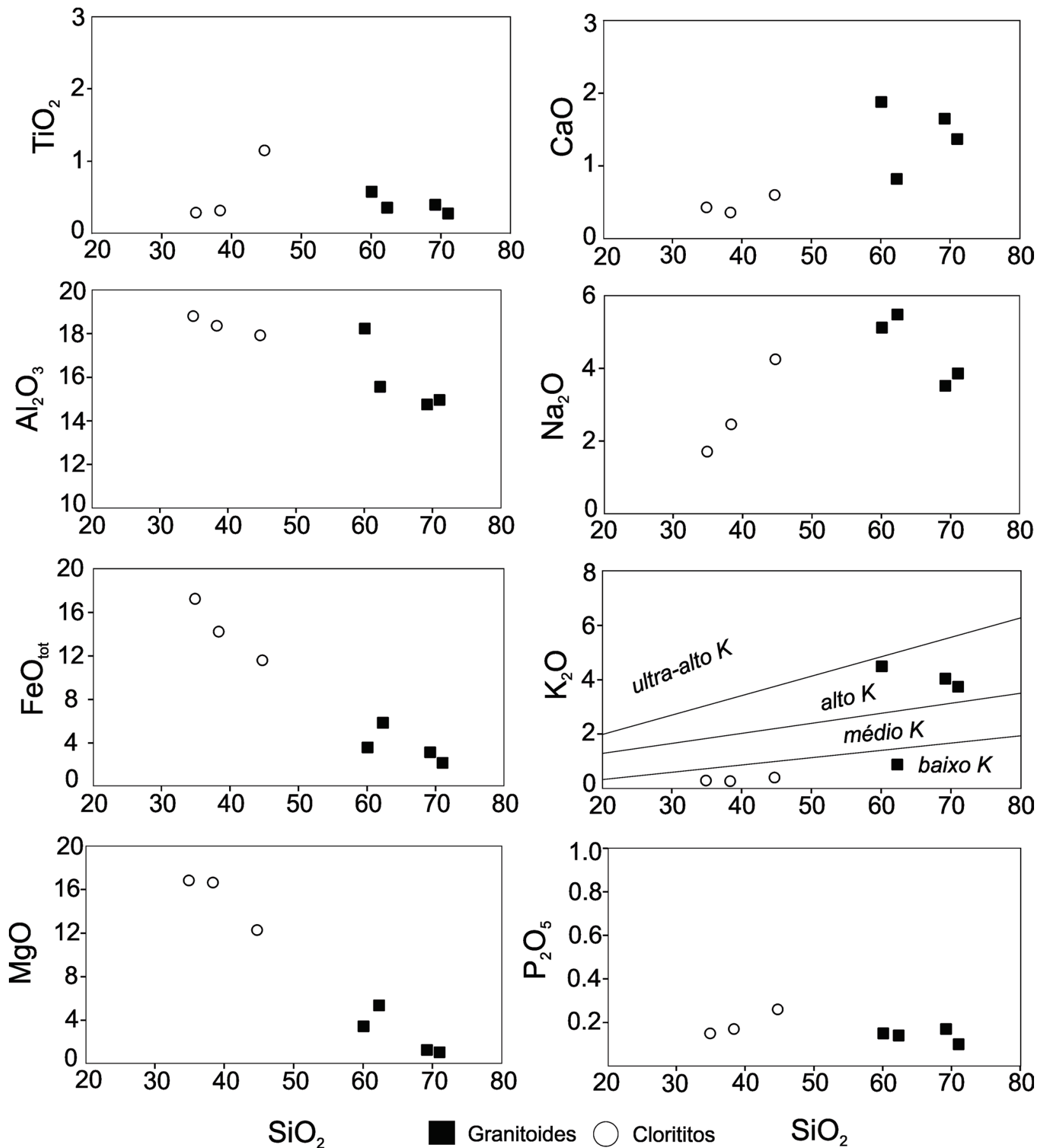

Figura 6. Diagrama de variação composicional do tipo Harker para óxidos das amostras analisadas utilizando $\mathrm{SIO}_{2}$. $\mathrm{FeO}_{\text {tot }}$ considerado como ferro total. 
Os diagramas ternários apresentados nas Figuras 10A e 10B relacionam o comportamento da evolução química entre biotita e clorita. Na Figura 10A, nota-se que há uma tendência de aumento de $\mathrm{FeO}+\mathrm{MgO}$ nas cloritas se comparadas às biotitas analisadas. No entanto, essa tendência se dá pelo aumento de $\mathrm{MgO}$ no sistema. Essa afirmativa pode ser mais bem observada na Figura 10B, em que nota-se a tendência do enriquecimento de $\mathrm{MgO}$ nos cristais de clorita se comparada a biotita - consequentemente, a perda de $\mathrm{SiO}_{2}$ das cloritas também pode ser verificada.

\section{Geotermometria}

Considerando apenas a composição química da clorita obtida por meio de análises pela microssonda eletrônica, optou-se por estimar as temperaturas por meio de rotinas empíricas de Cathelineau (1988) e Kranidiotis e MacLean (1987), descartando as rotinas baseadas em geotermômetros cristaloquímicos (Bourdelle et al., 2013; Inoue et al., 2009) devido à falta de parâmetros analíticos. A partir da abordagem empírica, a temperatura do mineral foi estimada de acordo com as equações constantes, conforme Tabela 8 , e aplicada em sistemas saturados em Al, cujos dados composicionais estão listados na Tabela 7. Um total de 31 cristais de clorita foi analisado em amostras do granito alterado e 15 cristais de clorita em hidrotermalito associado com sulfetos de $\mathrm{Cu}(\mathrm{Au})$. Para o granito alterado obteve-se temperaturas que variaram de 230 a $349^{\circ} \mathrm{C}$ e entre 237 e $325^{\circ} \mathrm{C}$, respectivamente. No hidrotermalito as temperaturas determinadas com as cloritas variaram de 249 a $319^{\circ} \mathrm{C}$ (Cathelineau, 1988) e entre 238 e $296^{\circ} \mathrm{C}$ (Kranidiotis e MacLean, 1987). As temperaturas médias (Tabela 8) obtidas em granito alterado e hidrotermalito variaram entre 280 e $300^{\circ} \mathrm{C}$, aproximadamente.

\section{Brechas hidrotermais}

As brechas investigadas neste trabalho situam-se proximamente das apófises ígneas. Apresentam clastos centimétricos

Tabela 3. Resultados quantitativos de ganhos e perdas da mobilidade química entre as amostras selecionadas. Relação $1-$ GR1-B $\rightarrow$ GR1-A, volume $(\%)=5,20$, massa $(\%)=-2,14$, slope=1,02. Relação $2-$ GR1-A $\rightarrow$ CL1, volume (\%)=-20,05, massa $(\%)=-31,04$, slope=1,45. Relação $3-\mathrm{GR} 1-\mathrm{B} \rightarrow \mathrm{CL1}$, volume $(\%)=-15,89$, massa $(\%)=-32,52$, slope=1,48.

\begin{tabular}{|c|c|c|c|c|c|c|c|c|c|c|c|c|}
\hline Composição & GR1-B & GR1-A & $\Delta \mathrm{C}_{i} / \mathrm{C}_{i}^{0}$ & $\Delta \mathrm{C}_{i}$ & GR1-A & CL1 & $\Delta \mathrm{C}_{i} / \mathrm{C}_{\mathrm{i}}{ }^{0}$ & $\Delta C_{i}$ & GR1-B & $\mathrm{CL1}$ & $\Delta \mathrm{C}_{i} / \mathrm{C}_{i}^{0}$ & $\Delta \mathrm{C}_{i}$ \\
\hline $\mathrm{SiO}_{2}$ & 71,04 & 62,32 & $-0,14$ & $-10,05$ & 62,32 & 34,90 & $-0,61$ & $-38,25$ & 71,04 & 34,90 & $-0,67$ & $-47,5$ \\
\hline $\mathrm{TiO}_{2}$ & 0,28 & 0,36 & 0,26 & 0,07 & 0,36 & 0,29 & $-0,44$ & $-0,16$ & 0,28 & 0,29 & $-0,30$ & $-0,08$ \\
\hline $\mathrm{Al}_{2} \mathrm{O}_{3}$ & 14,96 & 15,56 & 0,02 & 0,27 & 15,56 & 18,80 & $-0,17$ & $-2,60$ & 14,96 & 18,80 & $-0,15$ & $-2,27$ \\
\hline $\mathrm{Fe}_{2} \mathrm{O}_{3}$ & 2,16 & 5,85 & 1,65 & 3,57 & 5,85 & 17,24 & 1,03 & 6,04 & 2,16 & 17,24 & 4,39 & 9,47 \\
\hline $\mathrm{MnO}$ & 0,01 & 0,03 & 1,94 & 0,02 & 0,03 & 0,08 & 0,84 & 0,03 & 0,01 & 0,08 & 4,40 & 0,04 \\
\hline $\mathrm{MgO}$ & 1,07 & 5,36 & 3,90 & 4,18 & 5,36 & 16,84 & 1,17 & 6,25 & 1,07 & 16,84 & 9,62 & 10,30 \\
\hline $\mathrm{CaO}$ & 1,37 & 0,82 & $-0,41$ & $-0,57$ & 0,82 & 0,43 & $-0,64$ & $-0,52$ & 1,37 & 0,43 & $-0,79$ & $-1,08$ \\
\hline $\mathrm{Na}_{2} \mathrm{O}$ & 3,86 & 5,48 & 0,39 & 1,50 & 5,48 & 1,71 & $-0,78$ & $-4,30$ & 3,86 & 1,71 & $-0,70$ & $-2,71$ \\
\hline $\mathrm{K}_{2} \mathrm{O}$ & 3,74 & 0,88 & $-0,77$ & $-2,88$ & 0,88 & 0,29 & $-0,77$ & $-0,68$ & 3,74 & 0,29 & $-0,95$ & $-3,54$ \\
\hline $\mathrm{P}_{2} \mathrm{O}_{5}$ & 0,10 & 0,14 & 0,37 & 0,04 & 0,14 & 0,15 & $-0,26$ & $-0,04$ & 0,10 & 0,15 & 0,01 & 0,00 \\
\hline $\mathrm{Ba}$ & $1.657,00$ & 195,00 & $-0,88$ & $-1.466,10$ & 195,00 & 37,00 & $-0,87$ & $-169,49$ & $1.657,00$ & 37,00 & $-0,98$ & $-1.632,00$ \\
\hline $\mathrm{Be}$ & 3,00 & - & - & - & - & - & - & - & 3,00 & - & - & - \\
\hline Co & 2,90 & 4,10 & 0,38 & 1,11 & 4,10 & 6,20 & 0,04 & 0,18 & 2,90 & 6,20 & 0,44 & 1,28 \\
\hline Cs & 1,70 & 150,00 & $-0,14$ & $-0,23$ & 150,00 & 1,90 & $-0,13$ & $-0,19$ & 1,70 & 1,90 & $-0,25$ & $-0,42$ \\
\hline $\mathrm{Ga}$ & 14,20 & 13,20 & $-0,09$ & $-1,28$ & 13,20 & 22,30 & 0,16 & 2,18 & 14,20 & 22,30 & 0,06 & 0,85 \\
\hline $\mathrm{Hf}$ & 460,00 & 4,70 & 0,00 & 0,00 & 4,70 & 7,00 & 0,03 & 0,13 & 460,00 & 7,00 & 0,03 & 0,12 \\
\hline $\mathrm{Nb}$ & 10,00 & 12,90 & 0,26 & 2,62 & 12,90 & 10,70 & $-0,43$ & $-5,52$ & 10,00 & 10,70 & $-0,28$ & $-2,78$ \\
\hline $\mathrm{Ni}$ & 3,60 & 5,70 & 0,55 & 1,98 & 5,70 & 10,80 & 0,31 & 1,75 & 3,60 & 10,80 & 1,02 & 3,69 \\
\hline $\mathrm{Rb}$ & 85,90 & 31,40 & $-0,64$ & $-55,17$ & 31,40 & 13,90 & $-0,69$ & $-21,82$ & 85,90 & 13,90 & $-0,89$ & $-76,50$ \\
\hline Sc & 3,00 & 4,00 & 0,30 & 0,91 & 4,00 & 4,00 & $-0,31$ & $-1,24$ & 3,00 & 4,00 & $-0,10$ & $-0,30$ \\
\hline Sn & 2,00 & 2,00 & $-0,02$ & $-0,04$ & 2,00 & 3,00 & 0,03 & 0,07 & 2,00 & 3,00 & 0,01 & 0,02 \\
\hline $\mathrm{Sr}$ & 519,50 & 299,60 & $-0,44$ & $-226,30$ & 299,60 & 81,60 & $-0,81$ & $-243,33$ & 519,50 & 81,60 & $-0,89$ & -465 \\
\hline Ta & 0,80 & 1,10 & 0,35 & 0,28 & 1,10 & 0,90 & $-0,44$ & $-0,48$ & 0,80 & 0,90 & $-0,24$ & $-0,19$ \\
\hline Th & 6,30 & 8,60 & 0,34 & 2,12 & 8,60 & 10,60 & $-0,15$ & $-1,29$ & 6,30 & 10,60 & 0,14 & 0,85 \\
\hline U & 1,50 & 1,40 & $-0,09$ & $-0,13$ & 1,40 & 1,40 & $-0,31$ & $-0,43$ & 1,50 & 1,40 & $-0,37$ & $-0,56$ \\
\hline V & 23,00 & 35,00 & 0,49 & 11,25 & 35,00 & 37,00 & $-0,27$ & $-9,49$ & 23,00 & 37,00 & 0,09 & 1,97 \\
\hline Y & 10,50 & 13,90 & 0,30 & 3,10 & 13,90 & 16,60 & $-0,18$ & $-2,45$ & 10,50 & 16,60 & 0,07 & 0,70 \\
\hline $\mathrm{Zr}$ & 178,70 & 182,60 & 0,00 & 0,00 & 182,60 & 264,80 & 0,00 & 0,00 & 178,70 & 264,80 & 0,00 & 0,00 \\
\hline
\end{tabular}


cimentados por matriz composta majoritariamente por clorita. As interações metassomáticas entre as rochas e o fluido hidrotermal resultam em condições favoráveis para o aumento da pressão de voláteis $\left(\mathrm{H}_{2} \mathrm{O}\right.$ e $\left.\mathrm{CO}_{2}\right)$. Dessa forma, sugere-se que o mecanismo de formação das brechas seja o fraturamento hidráulico e que a fragmentação é causada pelo aumento da pressão de fluido. Sillitoe (1985) descreve e classifica como brecha magmática-hidrotermal feições e morfologias similares
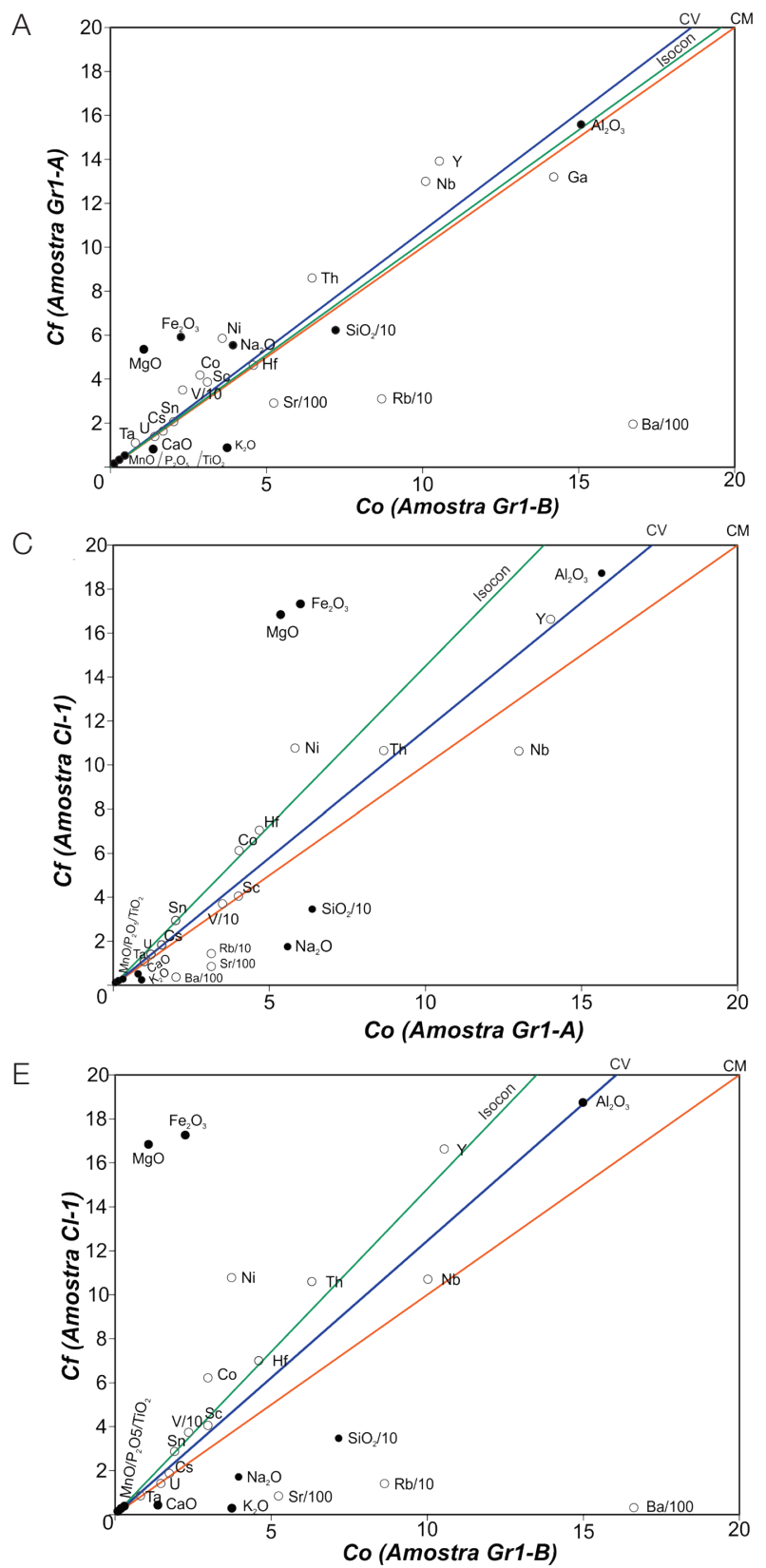

às identificadas neste estudo, atribuindo a formação desse tipo de brecha principalmente a quatro fatores:

1. Dissolução localizada e fragmentação por colapso gravitacional e/ou fraturamento hidráulico acima da intrusão por meio de fluidos oriundos de um magma em resfriamento;

2. Liberação, por vezes explosiva, de voláteis trazidos por um magma (fraturamento hidráulico);
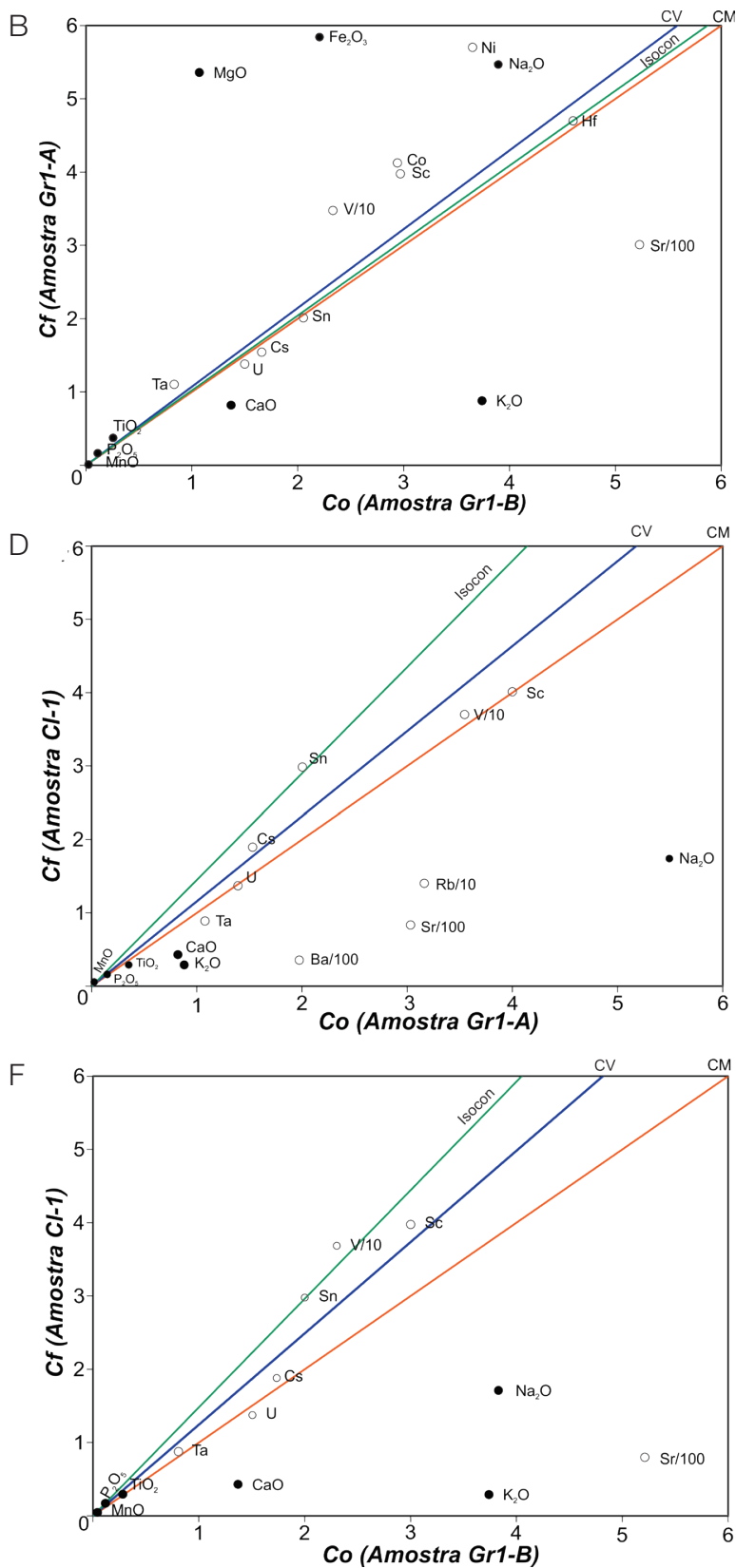

Eixo x: rocha não alterada; eixo y: rocha alterada; CV: isócona de volume constante; CM: isócona de massa constante; Isocon: isócona da mobilidade química; $\mathrm{TlO}_{2}$, $\mathrm{Hf}$ e $\mathrm{Zr}$ escolhidos como imóveis; $\mathrm{Fe}_{2} \mathrm{O}_{3}$ considerado como ferro total; •: Óxidos; o: Elementos-traço.

Figura 7. Diagramas de isóconas apresentando as mobilidades químicas entre as fases pré-alteração, intermediária e rocha alterada. 
Tabela 4. Composição química das amostras selecionadas. Concentração dos elementos terras raras em ppm.

\begin{tabular}{lccccccc}
\hline Amostra & SL-1 & GR1-A & GR1-B & GR2 & CL1 & CL2 & CL3 \\
\hline La & 74,700 & 73,400 & 40,100 & 66,000 & 70,600 & 113,700 & 74,600 \\
$\mathrm{Ce}$ & 128,000 & 122,900 & 65,400 & 114,400 & 126,900 & 219,400 & 131,700 \\
$\mathrm{Pr}$ & 12,960 & 11,850 & 6,200 & 10,700 & 11,830 & 23,120 & 12,730 \\
$\mathrm{Nd}$ & 43,200 & 37,300 & 21,400 & 35,700 & 38,900 & 86,400 & 43,000 \\
$\mathrm{Sm}$ & 6,920 & 5,290 & 2,890 & 5,210 & 5,750 & 14,670 & 6,590 \\
$\mathrm{Eu}$ & 1,240 & 1,300 & 0,760 & 1,310 & 1,370 & 3,250 & 1,250 \\
$\mathrm{Gd}$ & 5,540 & 3,920 & 2,350 & 4,240 & 4,300 & 11,700 & 4,940 \\
$\mathrm{~Tb}$ & 0,690 & 0,540 & 0,320 & 0,530 & 0,540 & 1,660 & 0,600 \\
$\mathrm{Dy}$ & 3,770 & 2,365 & 1,860 & 2,670 & 2,680 & 9,160 & 3,020 \\
$\mathrm{Ho}$ & 0,660 & 0,490 & 0,360 & 0,500 & 0,500 & 1,690 & 0,620 \\
$\mathrm{Er}$ & 2,000 & 1,490 & 0,990 & 1,360 & 1,400 & 4,720 & 1,520 \\
$\mathrm{Tm}$ & 0,310 & 0,210 & 0,160 & 0,230 & 0,220 & 0,690 & 0,250 \\
$\mathrm{Yb}$ & 1,890 & 1,410 & 1,220 & 1,620 & 1,500 & 4,960 & 1,680 \\
$\mathrm{Lu}$ & 0,320 & 0,230 & 0,160 & 0,260 & 0,220 & 0,700 & 0,250 \\
Total & 282,200 & 263,000 & 144,200 & 244,700 & 266,700 & 495,800 & 282,800 \\
(La/Sm)N & 5,920 & 7,610 & 7,610 & 6,940 & 6,730 & 4,250 & 6,200 \\
(La/Lu)N & 24,050 & 32,880 & 25,820 & 26,150 & 33,060 & 16,730 & 30,740 \\
(Lu/Gd)N & 0,423 & 0,429 & 0,498 & 0,449 & 0,374 & 0,438 & 0,370 \\
\hline
\end{tabular}
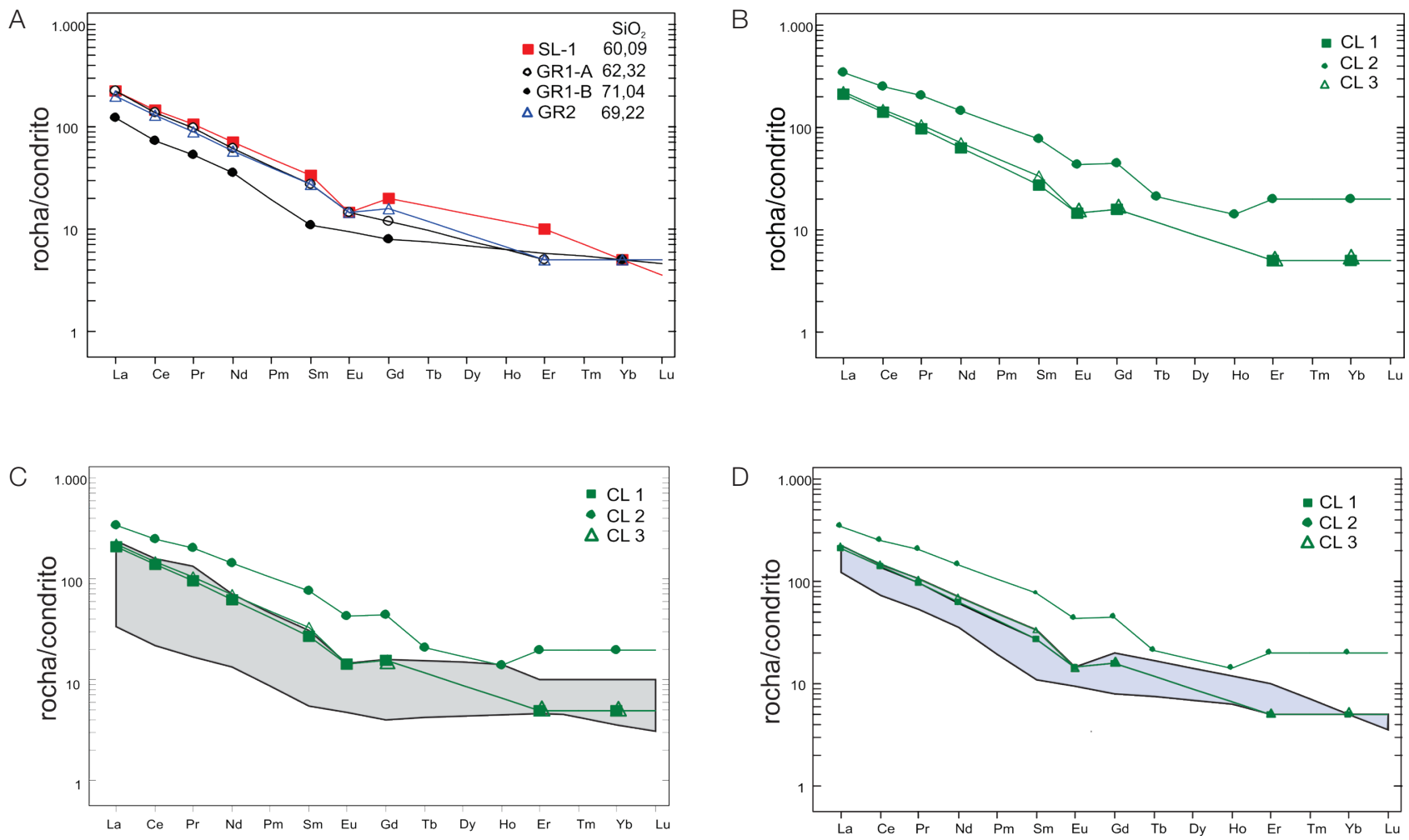

Figura 8. Curvas de abundâncias dos elementos terras raras dos diferentes grupos de amostras analisados normalizados pelo condrito de Haskin (1968). (A) Granitoides; (B) clorititos; (C) clorititos, região demarcada (biotita-granitoides e granitoides transicionais classificados por Nardi e Bitencourt, 1989); (D) clorititos, região demarcada (granitoides analisados neste trabalho). Obs.: O enriquecimento relativo da amostra CL2 indica que esta pertence a um protólito mais evoluído. 
Tabela 5. Síntese da composição química da biotita analisada em microssonda eletrônica (valores em wt\%).

\begin{tabular}{|c|c|c|c|c|c|c|c|c|c|c|c|c|c|c|}
\hline Mineral & $\mathrm{SiO}_{2}$ & $\mathrm{MgO}$ & $\mathrm{Al}_{2} \mathrm{O}_{3}$ & $\mathrm{~K}_{2} \mathrm{O}$ & $\mathrm{TiO}_{2}$ & $\mathrm{FeO}$ & $\mathrm{MnO}$ & $\mathrm{H}_{2} \mathrm{O}$ & Total & $\mathrm{Si}^{\mathrm{IV}}$ & $\mathrm{Mg}^{+2}$ & $\mathrm{Al}^{\mathrm{IV}}$ & $\mathrm{Al}^{\mathrm{II}}$ & $\mathrm{Fe}^{+2}$ \\
\hline $\begin{array}{l}\text { Média } \\
(\mathrm{n}=3)\end{array}$ & 35,97 & 9,79 & 1523 & 8,89 & 3,15 & 2170 & 0,09 & 3,88 & 98,90 & 5,56 & 2,26 & 2,44 & 0,34 & 2,82 \\
\hline $\mathrm{Bt}-1$ & 36,30 & $10,29^{\star}$ & 15,46 & 8,83 & 2,86 & & 0,06 & 3,88 & 8,35 & 5,60 & 2,36 & 2,39 & 0,41 & 2,64 \\
\hline Bt-7 & 36,28 & 8,96 & 14,99 & 9,38 & 2,96 & $23,22^{*}$ & 0,12 & 3,88 & 99,89 & 5,60 & 2,06 & 2,40 & 0,33 & 3,00 \\
\hline
\end{tabular}

${ }^{*}$ Maior teor do óxido entre as amostras analisadas; (-): valores não detectados pela análise. Os constituintes estruturais das biotitas foram obtidos a partir da fórmula química baseada em 22 oxigênios.

A

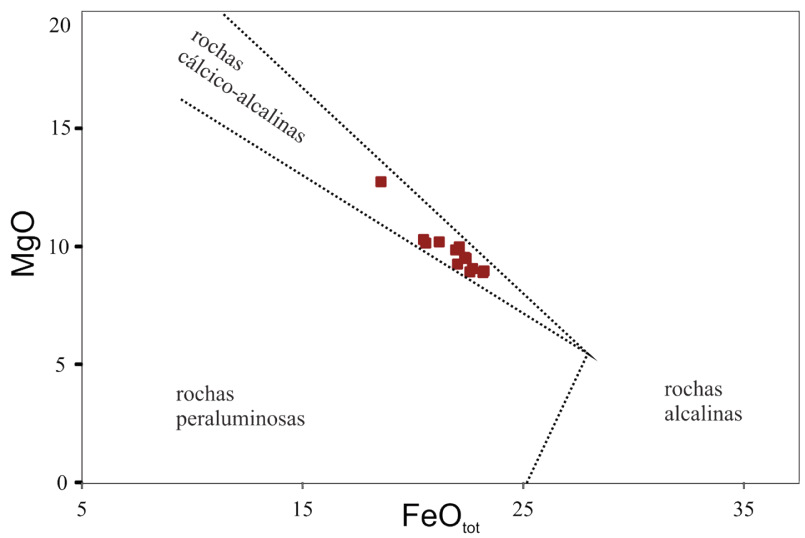

B

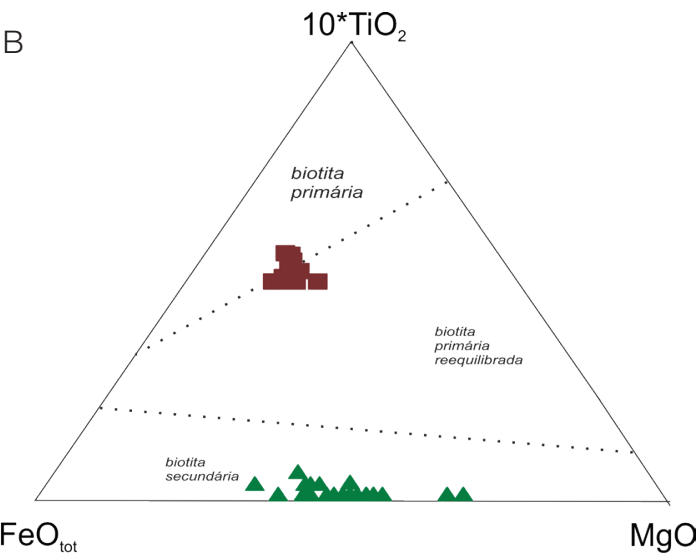

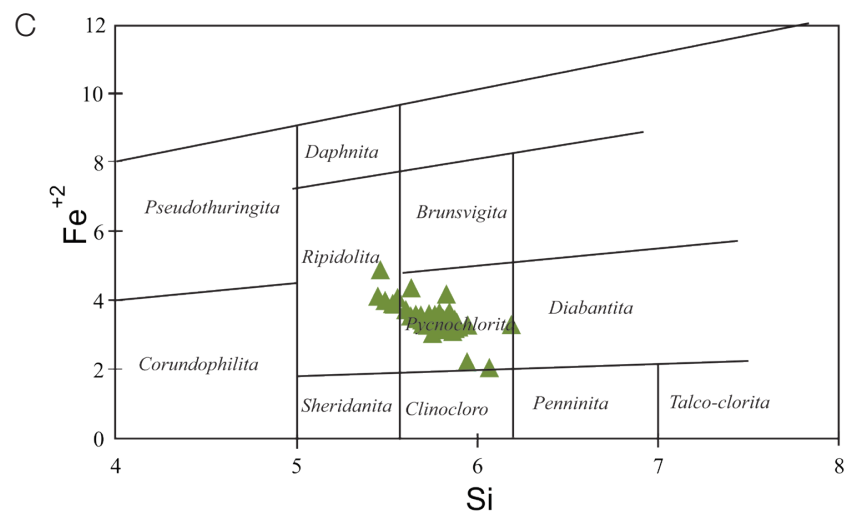

- Biotitas $\Delta$ Cloritas

Figura 9. Diagramas binário e ternário de classificação dos minerais analisados por microssonda eletrônica. (A) Classificação da série magmática da rocha a partir da composição da biotita (Abdel-Rahman, 1994); (B) diagrama ternário de reequilíbrio da biotita para clorita mostrando a perda de $\mathrm{TiO}_{2}$ no sistema (modificado de Panigrahi et al., 2008); (C) classificação da clorita por Hey (1954).

Tabela 6. Síntese da composição química do plagioclásio analisado em microssonda eletrônica (valores em wt\%).

\begin{tabular}{lccccccccccc}
\hline Mineral & $\mathrm{Na}_{2} \mathrm{O}$ & $\mathrm{SiO}_{2}$ & $\mathrm{MgO}$ & $\mathrm{Al}_{2} \mathrm{O}_{3}$ & $\mathrm{~K}_{2} \mathrm{O}$ & $\mathrm{CaO}$ & $\mathrm{FeO}$ & $\mathrm{MnO}$ & $\mathrm{TiO}_{2}$ & $\mathrm{BaO}$ & Total \\
\hline Média & 11,24 & 67,17 & 0,01 & 20,09 & 0,07 & 0,70 & 0,11 & 0,01 & 0,01 & 0,01 & 99,40 \\
$(\mathrm{n}=11)$ & 8,66 & 62,23 & 0,01 & 23,50 & 0,23 & $4,65^{\star}$ & 0,03 & 0,01 & - & - & 99,32 \\
$\mathrm{Pl}-1$ & $11,76^{*}$ & 67,38 & - & 19,84 & 0,05 & 0,28 & 0,02 & 0,01 & 0,02 & - & 99,36 \\
$\mathrm{Pl}-4$ &
\end{tabular}

*Maior teor do óxido entre as amostras analisadas; (-): valores não detectados pela análise. 
3. Produção de colapso gravitacional sobre a rocha por meio do movimento descendente do magma;

4. Desenvolvimento de uma bolha de fluido no teto de um plúton pelo acúmulo de fluidos liberados do magma, causando o colapso gravitacional acima dele.
O autor também considera que a característica da existência de fragmentos arredondados e com matriz granulometricamente muito fina sugere movimento entre clastos, e que entre os mecanismos envolvidos na brechação está a explosão de voláteis, seguida de descompressão e colapso

Tabela 7. Síntese da composição química da clorita analisada em microssonda eletrônica (valores em wt\%). Minerais com a nomenclatura Cel pertencem ao granito alterado; com a nomenclatura $\mathrm{Pcl}$, ao hidrotermalito. Os constituintes estruturais das cloritas foram obtidos a partir da fórmula química baseada em 28 oxigênios e $\mathrm{H}_{2} \mathrm{O}$ determinado por estequiometria.

\begin{tabular}{|c|c|c|c|c|c|c|c|c|c|c|c|c|c|}
\hline Mineral & $\mathrm{SiO}_{2}$ & $\mathrm{MgO}$ & $\mathrm{Al}_{2} \mathrm{O}_{3}$ & $\mathrm{TiO}_{2}$ & $\mathrm{FeO}$ & $\mathrm{MnO}$ & $\mathrm{H}_{2} \mathrm{O}$ & Total & $\mathrm{Sil}^{\mathrm{IV}}$ & $\mathrm{Mg}^{+2}$ & $\mathrm{Al}^{\mathrm{IV}}$ & $\mathrm{Al}^{\mathrm{VI}}$ & $\mathrm{Fe}^{+2}$ \\
\hline $\begin{array}{l}\text { Média } \\
(\mathrm{N}=31)\end{array}$ & 27,97 & 19,74 & 18,83 & 0,06 & 20,65 & 0,10 & 11,66 & 99,05 & 5,75 & 6,05 & 2,25 & 2,32 & 3,56 \\
\hline Cel-5 & 28,18 & $21,82^{*}$ & 18,79 & 0,03 & 17,86 & 0,08 & 11,75 & 98,52 & 5,75 & 6,64 & 2,24 & 2,27 & 3,04 \\
\hline Cel-27 & 25,75 & 14,39 & 20,17 & 0,12 & $27,58^{\star}$ & 0,20 & 11,30 & 99,55 & 5,46 & 4,55 & 2,53 & 2,50 & 4,89 \\
\hline $\begin{array}{l}\text { Média } \\
(\mathrm{N}=15)\end{array}$ & 28,42 & 21,00 & 18,63 & 0,04 & 19,43 & 0,09 & 11,78 & 99,46 & 5,79 & 6,37 & 2,21 & 2,26 & 3,32 \\
\hline Pcl-3 & 28,50 & 19,63 & 18,18 & 0,04 & $21,41^{*}$ & 0,10 & 11,69 & 99,61 & 5,84 & 6,00 & 2,15 & 2,24 & 3,67 \\
\hline Pcl-7 & 30,70 & $26,71^{*}$ & 16,93 & 0,04 & 12,45 & 0,06 & 12,14 & 99,04 & 6,06 & 7,86 & 1,93 & 2,00 & 2,05 \\
\hline
\end{tabular}

*Maior teor do óxido entre as amostras analisadas.

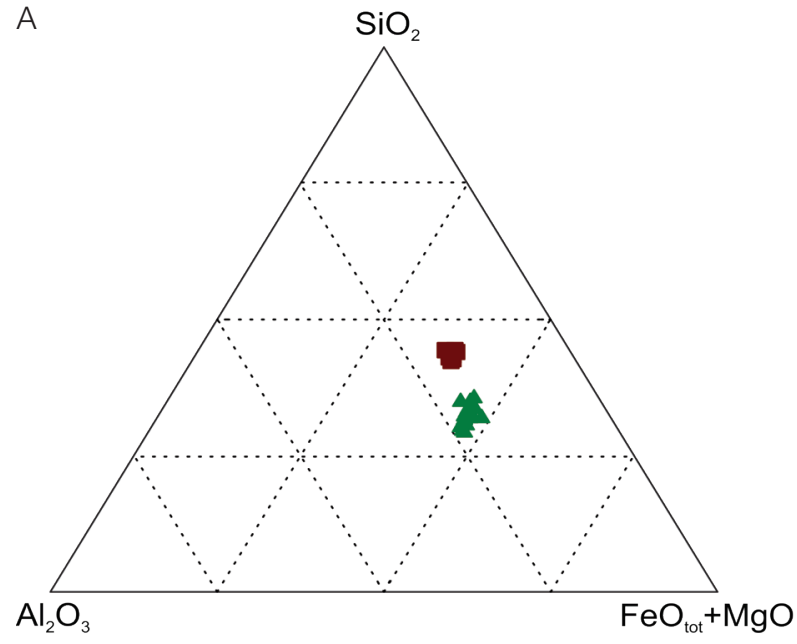

- Biotitas

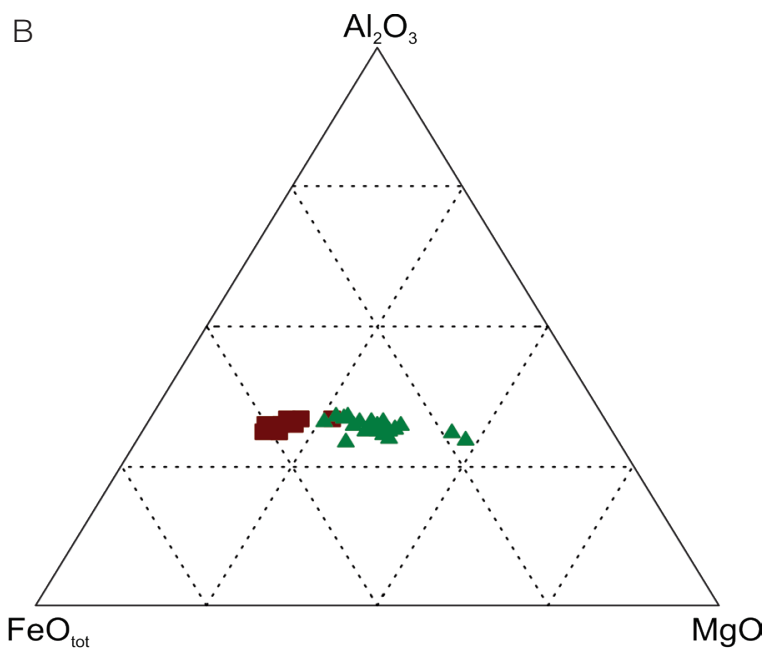

Cloritas

Figura 10. Diagramas ternários mostrando os campos de estabilidade dos minerais a partir de dados obtidos pela análise na microssonda eletrônica (modificado de Kranidiotis e MacLean, 1987). (A) Diagrama ternário composto pelos óxidos $\mathrm{SiO}_{2}$ e $\mathrm{Al}_{2} \mathrm{O}_{3}$ e pela soma $\mathrm{FeO}+\mathrm{MgO}$; (B) diagrama ternário composto pelos óxidos $\mathrm{Al}_{2} \mathrm{O}_{3}, \mathrm{FeO}$ e $\mathrm{MgO}$ mostrando o enriquecimento em $\mathrm{MgO}$ nas cloritas.

Tabela 8. Temperaturas inferidas a partir dos métodos empíricos aplicados para a clorita.

\begin{tabular}{lccc}
\hline Autor(es) & Fórmula aplicada & $\begin{array}{c}\text { Temperatura das cloritas }\left({ }^{\circ} \mathrm{C}\right) \\
\text { Granito alterado }\end{array}$ & $\begin{array}{c}\text { Temperatura das cloritas }\left({ }^{\circ} \mathrm{C}\right) \\
\text { Hidrotermalito }\end{array}$ \\
\hline $\begin{array}{l}\text { Cathelineau, 1988 } \\
\text { Kranidiotis e }\end{array}$ & $\mathrm{T}=-61,92+321,98 *{ }^{*} \mathrm{Al}$ & $300 \pm 26$ & $295 \pm 18$ \\
MacLean, 1987 & $\mathrm{Tl}^{\mathrm{IV}}=106 \mathrm{Al}{ }_{c}^{\mathrm{IV}}+18 ;$ & $284 \pm 20$ & $278 \pm 15$ \\
\hline
\end{tabular}


gravitacional; enquanto brechas clasto-suportadas com fragmentos angulosos provavelmente resultam de fraturamento hidráulico e colapso gravitacional por solução hidrotermal ou pelo acúmulo de fluido de um corpo intrusivo. Embora os processos de brechação não sejam excludentes, as características das brechas da área de Coronel Linhares sugerem que o acúmulo de fluidos e a presença da solução hidrotermal são os fatores dominantes para a formação das brechas, visto que a intrusão do magma como principal agente dos processos hidrotermais favorece esses fatores.

\section{Considerações metalogenéticas}

As rochas portadoras de cloritas, clorititos e os sulfetos presentes na região de estudo estão associadas diretamente aos processos metassomáticos e de alteração hidrotermal. Essas rochas apresentam uma paragênese formada majoritariamente por clorita, calcita e sulfetos de $\mathrm{Cu}(\mathrm{Au})$, como pirita e calcopirita. Por apresentarem uma paragênese mineral compatível com a alteração hidrotermal e com as observações de campo - indicando uma relação espacial direta entre os clorititos, os sulfetos e os granitoides - , o estudo sobre os processos de formação dos clorititos torna-se de suma importância para entender a gênese do minério de $\mathrm{Cu}(\mathrm{Au})$ na região. $\mathrm{O}$ fluido originalmente proveniente do granitoide interagiu com os mármores e se enriqueceu em $\mathrm{CO}_{2}$, por meio de reações de decarbonatação, e em alguns elementos, especialmente Mg. Durante a evolução do sistema, o fluido reagiu preferencialmente com a biotita dos granitoides, e em menor extensão com os plagioclásios, depositando clorita. $\mathrm{O}$ fluido atacou a biotita e depositou clorita, liberando $\mathrm{TiO}_{2}$, que combinou com o $\mathrm{Ca}$ dos plagioclásios ou proveniente do próprio mármore, depositando a titanita. A albita é mais restrita, mas originou-se da transformação do plagioclásio, originalmente oligoclásio-andesina. Possivelmente, a fonte dos metais presentes origina-se dos granitoides. Estima-se que o enxofre presente no fluido é produto da soma do elemento presente nos granitoides e nas rochas regionais, segundo Remus et al. (2000a). O S combinou-se com Fe e $\mathrm{Cu}$, liberados da biotita, depositando calcopirita e pirita.

\section{DISCUSSÃO E CONCLUSÕES}

Os processos de alteração hidrotermal que ocorrem entre os granitoides e as rochas encaixantes refletem uma transformação progressiva dos minerais da rocha protólito para os clorititos. A intrusão das apófises nas rochas carbonáticas encaixantes provoca reações que, em razão de fatores termodinâmicos, reequilibram os minerais formando novas paragêneses. Nas rochas encaixantes, ocorrem duas fases: uma de mais alta temperatura, caracterizada por apresentar estruturas dúcteis e paragênese mineralógica constituída majoritariamente por olivina, diopsídio e tremolita, com pirrotita e molibdenita associadas; e a outra de mais baixa temperatura, caracterizada pela paragênese mineralógica talco, calcita, serpentina e clorita, juntamente com pirita e calcopirita.

No processo de formação dos clorititos, entre os tipos de alterações hidrotermais na área destacam-se a cloritização e a albitização. A circulação dos fluidos $\mathrm{H}_{2} \mathrm{O}$ e $\mathrm{CO}_{2}$ nas rochas promove uma mobilidade química e uma consequente recristalização entre as apófises graníticas e as rochas encaixantes como resultado dessa transferência de fluidos. Analisando a mobilidade dos óxidos nos diagramas de isóconas, fica evidente o enriquecimento de $\mathrm{Fe}$ e $\mathrm{Mg}$ nas rochas durante todo o processo de alteração. Entre os estágios de pré-alteração e intermediário nota-se um enriquecimento relativo de sódio, o que sugere que a albitização ocorreu neste intervalo. $\mathrm{O}$ enriquecimento de $\mathrm{Mg}$ fica evidente também nos diagramas ternários de análise mineral entre biotita e clorita. Dentre as reações possíveis, sugere-se:

- biotita $+\mathrm{H}_{2} \mathrm{O}+\mathrm{MgO} \rightarrow$ clorita+rutilo;

- biotita $+\mathrm{H}_{2} \mathrm{O}+\mathrm{MgO}+\mathrm{CaO} \rightarrow$ clorita + titanita

As reações explicam as tendências de decréscimo de titânio e enriquecimento de $\mathrm{Mg}$ entre os minerais biotita e clorita. Na albitização, a formação de albita é resultado do processo de troca química de base enriquecendo em $\mathrm{Na}$ associado ao empobrecimento de $\mathrm{Ca}$. Paralelamente, a formação de sulfetos de $\mathrm{Cu}(\mathrm{Au})$ e rochas escarníticas também é resultado do reequilíbrio químico da percolação dos fluidos nas rochas encaixantes da Formação Passo Feio, sendo a associação de clorititos com zonas sulfetadas uma ocorrência comum no endoskarn. O acúmulo dos fluidos hidrotermais que circulam no sistema também é responsável pela ocorrência das brechas hidrotermais, dominantemente formadas por mecanismo de fraturamento hidráulico por solução hidrotermal.

As análises químicas dos padrões de abundância dos ETR das rochas indicam a presença de alteração propilítica. Entretanto, entende-se que a ausência de epídoto e argilização abundante indica um fluido hidrotermal com $\mathrm{pH}$ neutro a alcalino. Dessa forma, estima-se que as condições de $\mathrm{pH}$ e Eh dos fluidos estejam ligadas a um ambiente redutor, não favorecendo a epidotização. Um fator adicional a ser considerado é, possivelmente, a fração elevada de $\mathrm{CO}_{2}$, a qual pode inibir a formação do epídoto.

Considerando que os granitoides e os clorititos analisados apresentam comportamento químico similar ao dos ETR das fácies biotita-granitoide e granitoides transicionais, conclui-se que os clorititos apresentam correlação direta com os granitoides citados do Granito Caçapava, e com a alteração progressiva, sugere-se a presença de endoskarn. As análises composicionais dos granitoides e dos grãos de biotita indicam que as rochas pertencem à série cálcico-alcalina, conforme definido previamente por outros autores. 
As metodologias de geotermometria aplicadas nos cristais de clorita sugerem que os processos de alteração ocorrem em temperatura média entre $280 \mathrm{e} 300^{\circ} \mathrm{C}$, aproximadamente. No entanto, outras metodologias necessitam ser aplicadas para determinação mais eficaz da temperatura, bem como determinação de uma possível influência da água meteórica no sistema por meio de análises isotópicas.

\section{AGRADECIMENTOS}

À agência CAPES (Coordenação de Aperfeiçoamento de Pessoal de Nível Superior) pelo auxílio financeiro, ao Programa de Pós-Graduação em Geociências e ao Centro de Estudos em Petrologia e Geoquímica (CPGq) da Universidade Federal do Rio Grande do Sul (UFRGS).

\section{REFERÊNCIAS}

Abdel-Rahman, A. M. (1994). Nature of biotite from alkaline, calcalkaline and peraluminous magmas. Journal of Petrology, 35, 525-541. DOI: $10.1093 /$ petrology/35.2.525

Alderton, D. H. M., Pearce, J. A., Potts, P. J. (1980). Rare earth element mobility during granite alteration: evidence from the southwest England. Earth and Planetary Science Letters, 49, 149-165. DOI: 10.1016/0012-821X(80)90157-0

Almeida, F. F. M., Hasui, Y., Brito Neves, B. B. B. (1976). The upper Precambrian of South American. Boletim IG, Universidade de São Paulo, 7, 45-80. DOI: http://dx.doi. org/10.11606/issn.2316-8978.v7i0p45-80

Babinski, M., Chemale Jr., F., Hartmann, L. A., Van Schmus, W. R., Silva, L. C. (1996). Juvenile accretion at 750-700 Ma in southern Brazil. Geology, 24(5), 439-442. DOI: 10.1130/0091-7613(1996)024<0439:JAAMIS>2.3.CO;2

Babinski, M., Chemale Jr., F., Van Schmus, W. R., Hartmann, L. A., Silva, L. C. (1997). U-Pb and Sm-Nd geochronology of the Neoproterozoic granitic-gneissic Dom Feliciano Belt, Southern Brazil, Journal of South American Earth Sciences, 10(3), 263-274. DOI: 10.1016/S0895-9811(97)00021-7

Baker, J. H. (1985). Rare earth and other trace element mobility accompanying albitization in a Proterozoic granite, W. Bergslagen, Sweden. Mineralogical Magazine, 49, $107-$ 115. DOI: 10.1180/minmag.1985.049.350.17

Bitencourt, M. F. (1983). Geologia, petrologia e estrutura dos metamorfitos da região de Caçapava do Sul, RS. Simpósio Sul-Brasileiro de Geologia, p. 37-48. Porto Alegre: SBG.
Bortolotto, O. J. (1988). Metamorfismo termal dos mármores de Caçapava do Sul, RS. Ciência e Natura, 10, 25-48.

Bourdelle, F., Parra, T., Chopin, C., Beyssac, O. (2013). A new chlorite geothermometer for diagnostic low-grade metamorphic conditions. Contribution to Mineralogy and Petrology, 165, 723-735. DOI: 10.1007/s00410-012-0832-7

Bowden, P., Whitley, J. E. (1974). Rare-earth patterns in peralkaline and associated granites. Lithos, 7, 15-21. DOI: https://doi.org/10.1016/0024-4937(74)90033-4

Cathelineau, M. (1987). U-Th-REE mobility during albitization and quartz dissolution in granitoids: evidence from south-east French Massif Central. Bulletin de Mineralogie, 110(2-3), 249-259. DOI: https://inis.iaea.org/search/search. aspx?orig_q=RN:18085071

Cathelineau, M. (1988). Cation site occupancy in chlorites and ilites as a function of temperature. Clay minerals, $23,471-485$.

Chemale Jr., F. (2000). Evolução Geológica do Escudo Sul Rio-Grandense. In: M. Holz; L. F. De Ros (Eds.), Geologia do Rio Grande do Sul (13-52). Porto Alegre: Centro de Investigação do Gondwana, Instituto de Geociências, UFRGS.

Chemale Jr., F., Babinski, M. F., Hartmann, L. A., Schmus, W. R. (1994). Evolução tectônica do Bloco São Gabriel, RS. XXXVIII Congresso Brasileiro de Geologia, Boletim de Resumos Expandidos, n. 1, 626-627. Camboriú: SBG.

Costa, A. F. U., Shukowsky, W., Fernandes, L. A. D., Nardi, L. V. S., Bitencourt, M. F. (1995). Teste dos modelos tectônicos e de posicionamento do Complexo Granítico de Caçapava do Sul, através de estudos de modelagem gravimétrica 3-D. Revista Brasileira de Geofisica, 13(2), 91-101.

Deer, W. A., Howie, R. A., Zussman, J. (1966). Minerais constituintes das rochas: uma introdução. Lisboa: Fundação Calouste Gulbenkian. 558p.

Foster, M. D. (1962). Interpretation of the composition and a classification of the chlorites. Geological Survey Professional Paper 414-A, A1-A33. Washington, D.C.: Governo dos Estados Unidos.

Goulart, R. S., Remus, M. V. D., Reis, R. S. (2013). Composição Isotópica de $\mathrm{Sr}, \mathrm{C}$ e $\mathrm{O}$ e geoquímica de ETR das rochas carbonáticas do Bloco São Gabriel, Rio Grande do Sul. Pesquisas em Geociências, 40(1), 75-97. 
Grant, J. A. (1986). The isocon diagram: a simple solution to Gresens' equation for metasomatic alteration. Economic Geology, 81(8), 1976-1982. DOI: 10.2113/ gsecongeo.81.8.1976

Grant, J. A. (2005). Isocon analysis: a brief review of the method and application. Physics and Chemistry of the Earth, 30, 997-1004. DOI: 10.1016/j.pce.2004.11.003

Gresens, R. L. (1967). Composition-volume relationships of metasomatism. Chemical Geology, 2, 47-65. DOI: 10.1016/0009-2541(67)90004-6

Hartmann, L. A., Chemale Jr., F., Philipp, R. P. (2007). Evolução Geotectônica do Rio Grande do Sul no Pré-Cambriano. In: J. C. Frantz, R. Ianuzzi (Eds.), 50 anos de Geologia no Rio Grande do Sul (97-123). Porto Alegre: UFRGS-Petrobras.

Hartmann, L. A., Leite, J. A. D., Silva, L. C., Remus, M. V. D., McNaughton, N. J., Groves, D. I., Fletcher, I. R., Santos, J. O. S., Vasconcellos, M. A. Z. (2000a). Advances in SHRIMP geochronology and their impact on understanding the tectonic and metallogenic evolution of southern Brazil. Australian Journal of Earth Sciences, 47, 829-844. DOI: 10.1046/j.1440-0952.2000.00815.x

Hartmann, L. A., Philipp, R. P., Santos, J. O. S., McNaughton, N. J. (2011). Time Frame of 753-680 Ma juvenile accretion during the São Gabriel orogeny, Southern Brazil. Gondwana Research, 19(1), 84-99.

Hartmann, L. A., Porcher, C. C., Remus, M. V. D. (2000b). Evolução das rochas metamórficas do RS. In: M. Holz; L. F. De Ros (Eds.), Geologia do Rio Grande do Sul. Porto Alegre: Instituto de Geociências, UFRGS.

Hartmann, L. A., Tindle, A., Bitencourt, M. F. (1990). O metamorfismo de fácies anfibolito no Complexo Passo Feio, RS com base em química dos minerais. Pesquisas, 17(1-2), 62-71.

Haskin, L. A., Haskin, M. A., Frey, F. A., Wildeman, T. R. (1968). Relative and absolute terrestrial abundances of the rare earths. In: L. H. Ahrens (Ed.), Origin and distribution of the Elements (889-912). DOI: doi.org/10.1016/ B978-0-08-012835-1.50074-X

Hey, M. H. (1954). A new review of the chlorites. The mineralogical Magazine, 30, 278-292.

Humphris, S. E., Thompson, G. (1978). Hydrothermal alteration of oceanic basalts by seawater. Geochimica Cosmochimica, Acta 42, 107-125. DOI: 10.1016/0016-7037(78)90221-1
Inoue, A., Meunier, A., Patrier-Mas, P., Rigault, C., Beaufort, D., Vieillard, P. (2009). Application of Chemical Geothermometry to Low-Temperature Trioctahedral Chlorites. Clays and Clay Minerals, 57(3), 371-382. DOI: 10.1346/ CCMN.2009.0570309

Jensen, L. S. (1976). A new cation plot for classifying subalkaline volcanic rocks. Ontário: Ministry of Natural Resources. 22p.

Jost, H., Hartmann, L. A. (1984). Província Mantiqueira Setor meridional. In: F. F. M. Almeida, Y. Hasui (Eds.). O PréCambriano do Brasil (345-367). São Paulo: Edgard Blucher.

Kranidiotis, P., MacLean, W. H. (1987). Systematic of chlorite alteration at the Phelps Dodge massive sulfide deposit, Matagoni, Quebec. Economic Geology, 82(7), 1898-1911. DOI: 10.2113/gsecongeo.82.7.1898

López-Moro, F. J. (2012). EASYGRESGRANT - A Microsoft Excel spreadsheet to quantify volume changes and to perform mass-balance modeling in metasomatic systems. Computers e Geosciences, 39, 191-196. DOI: 10.1016/j.cageo.2011.07.014

McLeod, R. L., Stanton, R. L. (1984). Phyllosilicates and associated minerals in some Paleozoic stratiform sulfide deposits in Southeastern Australia. Economic Geology, 79, 1-22. DOI: 10.2113 /gsecongeo.79.1.1

Middlemost, A. K. (1994). Naming material in the magma/ Igneous rock system. Earth-Science Reviews, 37, 215-224. DOI: 10.1016/0012-8252(94)90029-9

Miyashiro, A., Shido, F., Kanehira, K. (1979). Metasomatic chloritization of gabbros in the Mid-Atlantic Ridge near $30^{\circ} \mathrm{N}$. Marine Geology, 31, M47-M52. DOI: 10.1016/0025-3227(79)90052-5

Morteani, G., Möller, P., Hoefs, J. (1986). Rare-earth element and oxygen isotope studies of altered variscan granites: the western Harz (Germany) and southern Sardinia (Italy). Chemical Geology, 54, 53-68. DOI: 10.1016/0009-2541(86)90071-9

Mottl, M. J., Holland, H. D. (1978). Chemical exchange during hydrothermal alteration of basalt by seawater -1 . Experimental results for major and minor components of seawater. Geochimica et Cosmochimica Acta, 42, 11031115. DOI: 10.1016/0016-7037(78)90107-2

Nardi, L. V. S., Bitencourt, M. F. (1989). Geologia, petrologia e geoquímica do Complexo Granítico de Caçapava do Sul, RS. Revista Brasileira de Geociências, 19(2), 153-169. 
Panigrahi, M. R., Naik, R. K., Pandit, D., Misra, K. C. (2008). Reconstructing physico-chemical parameters of hydrothermal mineralization of copper at the Malanjkhand deposit, India, from mineral chemistry of biotite, chlorite and epidote. Geochemical Journal, 42, 443-460. DOI:10.2343/geochemj.42.443

Pirajno, F. (1992). Hydrothermal mineral deposits: principles and fundamental concepts for the exploration geologist. Nova York: Springer-Verlag. 709p. DOI: 10.1007/978-3-642-75671-9

Remus, M. V. D., Dani, N., Gazzoni, C. P., Hoerlle, G. S., Reis, R. S. (2011). Minério de $\mathrm{Cu}(\mathrm{Au})$ de alto teor em zonas de alteração clorítica em escarnitos magnesianos de Caçapava do Sul, RS. XIII Congresso Brasileiro de Geoquímica, CD-ROM: CGQ07_T16. Gramado: SBGq.

Remus, M. V.D., Hartmann, L. A., McNaughton, N. J., Groves, D. I., Fletcher, I. R. (2000a). The link between hydrotermal epigenetic copper mineralization and the Caçapava Granite of the Brasiliano Cycle in Southern Brazil. Journal of South American Earth Sciences, 13, 191-216. DOI: 10.1016/S0895-9811(00)00017-1

Remus, M. V. D., Hartmann, L. A., McNaughton, N. J., Groves, D. I., Reischl, J. L. (2000b). Distal magmatic-hydrothermal origin for the Camaquã $\mathrm{Cu}(\mathrm{Au}-\mathrm{Ag})$ and Santa Maria $\mathrm{Pb}$, $\mathrm{Zn}(\mathrm{Cu}-\mathrm{Ag})$ deposits, southern Brazil. Gondwana Research, 3(2), 155-174. DOI: 10.1016/S1342-937X(05)70094-0

Ribeiro, M., Bocchi, P. R., Figueiredo Filho, P. M., Tessari, R. I. (1966). Geologia da quadrícula de Caçapava do Sul, RS, Brasil. Boletim da Divisão de Geologia e Mineralogia, 127-232.

Ribeiro, M., Carraro, C. C. (1971). Geotectonic Map of the Caçapava do Sul region - RS, Brazil. Porto Alegre: UFRGS/ Instituto de Geociências.

Rollinson, M. R. (1993). Using geochemical data: evaluation, presentation, interpretation. NovaYork: Longman. 352p.
Ruiz, C., Arribas, A., Arribas Jr., A. (2002). Mineralogy and geochemistry of the Masa Valverde blind massive sulphide deposit, Iberian pyrite belt (Spain). Ore Geology Reviews, 19, 1-22. DOI: 10.1016/S0169-1368(01)00037-3

Sartori, P. L. P., Kawashita, K. (1985). Petrologia e geocronologia do Batólito Granítico de Caçapava do Sul-RS. II Simpósio Sul-Brasileiro de Geologia, Anais, 102-115. Florianópolis: SBG.

Schermerhorn, L. J. (1978). Epigenetic magnesium metasomatism or syngenetic chloritite metamorphism at Falun and Orijarvi. Transactions of the Institute of Mining and Metallurgy, 87, B162-B167.

Schiffman, P., Staudigel, H. (1995). The smectite to chlorite transition in a fossil seamount hydrothermal system: the Basement Complex of La Palma, Canary Islands. Journal of Metamorphic Geology, 13(4), 487-498. DOI: 10.1111/ j.1525-1314.1995.tb00236.x

Sillitoe, R. H. (1985). Ore-related breccias in volcanoplutonic arcs. Economic Geology, 80(6),1467-1514. DOI: 10.2113/gsecongeo.80.6.1467

Soliani Jr., E. (1986). Os dados geocronológicos do escudo sul-riograndense e suas implicações de ordem geotectônica. Tese (Doutorado). São Paulo: Instituto de Geociências - USP. DOI: 10.11606/T.44.1986.tde-15072015-153916

Ward, C. D., McArthur, J. M., Walsh, J. N. (1992). Rare earth element behaviour during evolution and alteration of the Dartmoor granite, SW England. Journal of Petrology, 33, 785-815. DOI: 10.1093/petrology/33.4.785

Zang, W., Fyfe, W. S. (1995). Chloritization of the hydrothermally altered bedrock at the Igarapé Bahia gold deposit, Carajás, Brazil. Mineralium Deposita, 30(1), 30-38. DOI: $10.1007 / \mathrm{BF} 00208874$ 